\title{
Challenging Evaluation of the Hybrid Technique of Chemical Engineering - Proton NMR Technique for Food Engineering
}

\author{
Yasuyuki Konishi ${ }^{1,}{ }^{*}$ and Masayoshi Kobayashi ${ }^{2}$ \\ ${ }^{1}$ Hokkaido Industrial Technology Center, \\ 379 Kikyo-cho, Hakodate, Hokkaido \\ ${ }^{2}$ Advanced Technology Institute of Northern Resources, \\ 8-6, Tonden 2-Jo, 2-Chome, Sapporo, Hokkaido \\ Japan
}

\section{Introduction}

In the field of food engineering, chemical engineering and bioengineering have commonly used the data obtained from physicochemical techniques. In particular, water species are strongly related to food quality, as has been demonstrated in the International Symposium on Properties of Water (Eds. Rockland and Stewart, 1981). The water species retained in foods, as is well known, expose their multifunctional nature by dynamically responding to environmental conditions such as temperature, pressure, dehydration processes, water content, etc. For scientific analysis of the multifunctional water species retained in foods, of particular difficulty is the influence of nonlinear dynamic change on food quality. To quantitatively evaluate the nature of the water species, a large number of researchers have demonstrated the diversity of their biological and physicochemical nature using various parameters. The water activity $\left(\mathrm{a}_{\mathrm{w}}\right)$ has, for example, commonly been used as a parameter to evaluate the deterioration of foods (Fennema, 1976). The effective water diffusivity parameter $(D e)$ in foods has also frequently been employed to evaluate the dehydration rate (Jason, 1958). From the chemical engineering point of view, this is a typical procedure in evaluating water mobility in the food tissue matrix. Conversely, for direct identification of the water species at the molecular level, magnetic resonance techniques have been applied to evaluate food quality, as demonstrated in the International Conferences on Applications of Magnetic Resonance in Food Science (Eds. Belton et al., 2003).

In our previous papers (Konishi et al., 2001, 2003), using separately chemical engineering and proton NMR techniques, water species retained in fish paste sausage and squid were roughly distinguished into two different species as a function of water content. The two species were water species $A_{1}$, to be recognized as the higher water content at $W_{0}>120 \%$-d.b. accompanied by higher water diffusivity, $D e$, and water species $A_{2}, W_{0}<120 \%$-d.b., with lower $\mathrm{De}$. This delineation, however, was unclear because of a vagueness of the boundary

* Corresponding Author 
between the two water species. To clearly discriminate between the two water species, a new technique is needed for the design of food products. In the present study, responding to this need, a hybrid technique derived from joint research using chemical engineering techniques and proton NMR techniques was proposed. The aims of this study are: (1) to demonstrate the dynamism of water species influenced by the change of environmental conditions and the dynamic transformation between the two water species, $\mathrm{A}_{1}$ and $\mathrm{A}_{2} ;(2)$ to quantitatively visualize the limitations of both the chemical engineering technique and the proton NMR technique; (3) to apply a hybrid technique in choosing specified design parameters in order to clearly identify differences between the two water species and among a variety of food products; and (4) to classify twelve commercial jerky products, as a typical example, into a few groups based on the characterization of design parameters using the hybrid technique.

\section{Experimental methods of the hybrid technique}

\subsection{Methods}

Six commercially distributed beef and pork jerkies, (BJ-1 BJ-6) and (PJ-1 PJ-6), respectively, a pork meat (designated $\mathrm{P}_{\mathrm{H}}$, used as a reference meat) produced in Hokkaido, two beef meats $\left(\mathrm{B}_{\mathrm{A}}\right.$ : produced in Australia, and $\mathrm{B}_{\mathrm{H}}$ : produced in Hokkaido), salmon (SM), and squid (SQ) were chosen as the food samples. All samples used in this study were tabulated in Table 1. The commercial jerkies used were characterized as having a water content range

\begin{tabular}{|c|l|c|}
\hline & \multicolumn{1}{|c|}{ Features } & Group No. \\
\hline PJ-1 & soy-sauce base taste, about $1.0 \mathrm{~mm}$ thick & 2 \\
\hline PJ-2 & soy-sauce base taste, $1.1 \sim 1.4 \mathrm{~mm}$ thick & 1 \\
\hline PJ-3 & light taste, oily, smoked flavor, $0.8 \sim 5.9$ mm thick & 2 \\
\hline PJ-4 & salt base taste, smoked flavor, strong taste, hard, $2.2 \sim 4.8 \mathrm{~mm}$ thick & 2 \\
\hline PJ-5 & salt base taste, smoked flavor, strong taste, soft, $1.3 \sim 2.7 \mathrm{~mm}$ thick & 3 \\
\hline PJ-6 & soy-sauce base taste, light taste, hard, $1.9 \sim 3.5 \mathrm{~mm}$ thick & 3 \\
\hline BJ-1 & salt base taste, light taste, hard, $1.4 \sim 2.2 \mathrm{~mm}$ thick & 2 \\
\hline BJ-2 & salt base taste, strong taste, soft, about $2.2 \mathrm{~mm}$ thick & 3 \\
\hline BJ-3 & miso-sauce base taste, strong taste, soft, $4.2 \sim 5.9$ mm thick & 3 \\
\hline BJ-4 & salt base taste, light taste, soft, $1.6 \sim 3.1 \mathrm{~mm}$ thick & 2 \\
\hline BJ-5 & soy-sauce base taste, strong taste, hard, $3.1 \mathrm{~mm}$ thick & 2 \\
\hline BJ-6 & salt base taste, light taste, hard, $0.9 \sim 2.8 \mathrm{~mm}$ thick & \\
\hline$P_{\mathrm{H}}$ & $\begin{array}{l}\text { pork meat produced in Hokkaido, soy-sauce base taste, hard, about } \\
6 \pm 1.0 \text { mm thick }\end{array}$ & \\
\hline$B_{\mathrm{H}}$ & beef meat produced in Hokkaido, about $8 \pm 1.0 \mathrm{~mm}$ thick & \\
\hline $\mathrm{B}_{\mathrm{A}}$ & beef meat produced in Australia, about $8 \pm 1.0 \mathrm{~mm}$ thick & \\
\hline SQ & squid mantle, $50 \times 50 \times 7 \pm 1.5$ mm & \\
\hline SM & salmon, $50 \times 15 \times 12 \sim 26$ mm & \\
\hline
\end{tabular}

Table 1. Features of the pork meat $\left(\mathrm{P}_{\mathrm{H}}\right)$, beef meat $\left(\mathrm{B}_{\mathrm{A}}\right.$ and $\left.\mathrm{B}_{\mathrm{H}}\right)$, squid $(\mathrm{SQ})$, salmon $(\mathrm{SM})$, and the commercial jerkies used for this study. PJ-1 -6: pork jerkies; BJ-1 -6: beef jerkies. 
of $30 \sim 80 \%$-d.b. (dry base, $W_{\mathrm{D}}$ ), the pork and beef meats had the initial water contents of 230 320\%-d.b. and 230 280\%-d.b., respectively, and the initial water content of the salmon and the squid commonly ranged from 300 360\%-d.b. To evaluate the effective diffusivity $(D e)$ of water species, each of the samples was placed in a stainless steel net tray (4 meshes) that was mechanically hung from a strain gage transducer in the dryer. The sample weight was, to evaluate the dehydration rate, continuously recorded by the output of strain-gage transducer using a data-logger. With molecular-level analysis, to evaluate the correlation time $\left(\tau_{\mathrm{C}}\right)$ of the water species in the salmon, squid, 12 jerkies, $\mathrm{B}_{\mathrm{H}}, \mathrm{B}_{\mathrm{A}}$, and $\mathrm{P}_{\mathrm{H}}$, a nuclear magnetic resonance (NMR) technique was applied to measure the ${ }^{1} \mathrm{H}-\mathrm{NMR}$ spectra and the spin-spin relaxation time $\left(T_{2}\right)$ of water protons. All samples, cut into $2 \times 2 \times 10 \mathrm{~mm}$ pieces, were inserted into an NMR sample tube (4mm in inner diameter, $180 \mathrm{~mm}$ in length). ${ }^{1} \mathrm{H}-$ NMR spectra were obtained using a JEOL A-500 FT-NMR spectrometer operating at $500 \mathrm{MHz}$ for protons. The observed frequency width was $20 \mathrm{kHz}$. The $90^{\circ}$ pulse width was $12.5 \mu \mathrm{s}$, and the number of pulse repetitions was 8. The proton chemical shifts were measured by using a slight amount of water containing deuterium oxide as an external reference. All the NMR measurements were performed at $23.5 \pm 0.5^{\circ} \mathrm{C}$. The spin-spin relaxation times, $T_{2}$, were obtained by the spin locking method. The hardness $\left(\mathrm{N} / \mathrm{m}^{2}\right)$ of the samples was measured using a creep tester equipped with a V-shaped plunger $(30 \mathrm{~mm}$ wide, $1 \mathrm{~mm}$ thick) to press a $60 \%$ of the sample size of $2 \sim 8 \times 10 \times 50 \mathrm{~mm}$.

\subsection{Evaluation of the parameters}

\subsubsection{Effective diffusion coefficient $(D e)$ of water species}

As has been reported by a large number of researchers (Andreu and Stamatopoulos, 1986; Waananen and Okos, 1996; Litchfield and Okos, 1992; Kannan and Bandyopadhyay, 1995), diverse mathematical equations for evaluating the effective diffusion coefficient $(D e)$ of water in foods have been demonstrated in various forms. In the present study, $D e^{\prime}$ s of all the samples were evaluated by applying Equation (1) to the dehydration response curves obtained. In the present experimental drying conditions, it was reconfirmed that the drying operations were within a falling-rate period. Through all the evaluation of $D e$, the effect of the shrinkage of the samples (derived from the dehydration) on the values obtained was previously evaluated, and the sizes of the samples were corrected.

$$
\frac{W-W e}{W_{D}-W e}=\left(\frac{8}{\Pi^{2}}\right)^{3} \exp \left(\frac{-\Pi^{2} \cdot D e \cdot t}{4} \cdot\left(L_{a}^{-2}+L_{b}{ }^{-2}+L_{c}^{-2}\right)\right)
$$

Where $W$ is the water content (\%-d.b.) of the sample at $t=t(\mathrm{~h}), W e$ is the equilibrium water content (\%-d.b.), $W_{\mathrm{D}}$ is the water content (\%-d.b.) at the given initial condition, $D e$ is the effective diffusion coefficient $\left(\mathrm{m}^{2} / \mathrm{h}\right)$ of water species retained in the foods, $L_{\mathrm{a}}, L_{\mathrm{b}}$, and $L_{\mathrm{c}}(\mathrm{m})$ are the half distances of the sample width, and $t$ is dehydration time (h).

$D e$ is represented as a function of the structure parameters (porosity and labyrinth factor) of food and the activation energy, as shown in Equation (2).

$$
D e=\left(\frac{\varepsilon}{\chi}\right) \cdot D=\delta \cdot D_{0} \cdot \exp \left[\frac{-E_{\mathrm{D}}}{R \cdot\left(T_{\mathrm{D}}+273\right)}\right]
$$


Where $\varepsilon$ is porosity, $\chi$ is labyrinth factor, $D$ is diffusivity $\left(\mathrm{m}^{2} / \mathrm{h}\right), D_{0}$ is the frequency factor of $D, \delta$ is diffusibility $(=\varepsilon / \chi), E_{\mathrm{D}}$ is activation energy of $D e, R$ is gas constant, and $T_{\mathrm{D}}$ is drying temperature.

The pre-exponential factor, $\delta \cdot D_{0}$, can be a useful tool to discriminate between the water species retained in different kinds of foods, as is described in upcoming sections.

\subsubsection{Correlation time $\left(\tau_{\mathrm{C}}\right)$ of water protons}

The spin-locking pulse technique used was effective in detecting a very fast relaxation signal at low water contents. For evaluation of the relaxation time, $T_{2}$, the equation $M_{t}=M_{0} \exp (-$ $t_{s} / T_{2}$ ) was used, where $M_{t}$ is the magnitude of the magnetization vector after the spin locking pulse, $M_{0}$ is magnitude of the macroscopic equilibrium magnetization vector, and ts is the spin locking pulse length. In the present study, the plot of $\ln \left[M_{t} / M_{0}\right]$ vs. ts indicated good linearity (which demonstrates a correlation coefficient higher than 0.99) through all water content of the foods, suggesting that the evaluated $T_{2}$ value was reasonable. From $T_{2}$, the correlation time of a water proton, $\tau_{C}$, was evaluated using Equation (3) as described by Abragam (1963):

$$
\frac{1}{T_{2}}=\frac{r^{4} \cdot \hbar^{2} \cdot I(I+1)}{5 r^{6}}\left(3 \tau_{c}+\frac{5 \tau_{c}}{1+\omega_{0}{ }^{2} \cdot \tau_{c}{ }^{2}}+\frac{2 \tau_{c}}{1+4 \omega_{0}{ }^{2} \cdot \tau_{c}{ }^{2}}\right),
$$

where $\gamma$ is the gyromagnetic ratio of a proton $\left(=2.675 \times 10^{8} \operatorname{rad}^{-1} \mathrm{~T}^{-1} \mathrm{~s}^{-1}\right), \hbar$ is the modified Plank's constant $\left(6.63 \times 10^{-34} \mathrm{~J} \cdot \mathrm{s}\right), I$ is the nuclear-spin quantum number of a water proton $(=$ $0.5), r$ is the proton-proton distance of a water molecule $(0.16 \mathrm{~nm}), \omega_{0}$ is the resonance frequency of $\operatorname{NMR}\left(=3.14 \times 10^{9} \mathrm{~s}^{-1}\right)$, and $\tau_{\mathrm{C}}$ is the correlation time of a water proton $(\mathrm{s})$.

\section{Dynamic transformation of water species retained in foods}

\subsection{Variety of water species in foods}

\subsubsection{Visualization from the proton NMR technique}

The water species retained in foods are dynamically changed into multifunctional states according to environmental conditions such as temperature, atmospheric pressure, atmospheric relative humidity, seasoning components such as salt and sugar, concentration of seasoning components, etc. Figure 1 is a schematic explanation of the water species adsorbed on macromolecules such as proteins in foods. The water species are classified into three groups as: (1) monolayer adsorbed water localized in region-I, which is referred to as bond water, immobilized water, or non-freezing water; (2) multi-adsorbed water localized in region-II, which is referred to as strongly restricted water, glass-state water, etc.; and (3) free water localized in region-III, which is referred to as normal isotropic bulk water, capillary condensation water, etc. The proton NMR technique produced correlation times of the three regions, I, II, and III, as $\tau_{\mathrm{C}}=10^{-6 \sim-7} \mathrm{~S}, 10^{-6 \sim-11} \mathrm{~s}$, and $10^{-12} \mathrm{~s}$, respectively. This classification is interestingly correlated to the three regions of the adsorption isotherm evaluated by the chemical engineering technique, as shown in Figure 2 by curve 1 . As has been reported in previous papers (Konishi et al., 2003, 2010), water species in the three regions are dynamically transformed by each other depending on environmental conditions in 


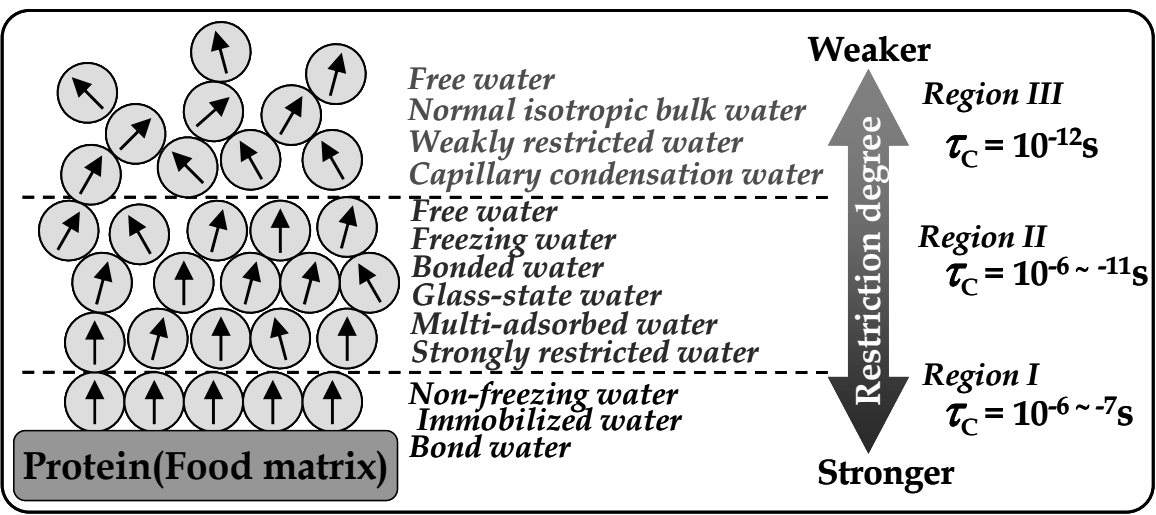

Fig. 1. Schematic explanation of the water species adsorbed on macromolecules in food.
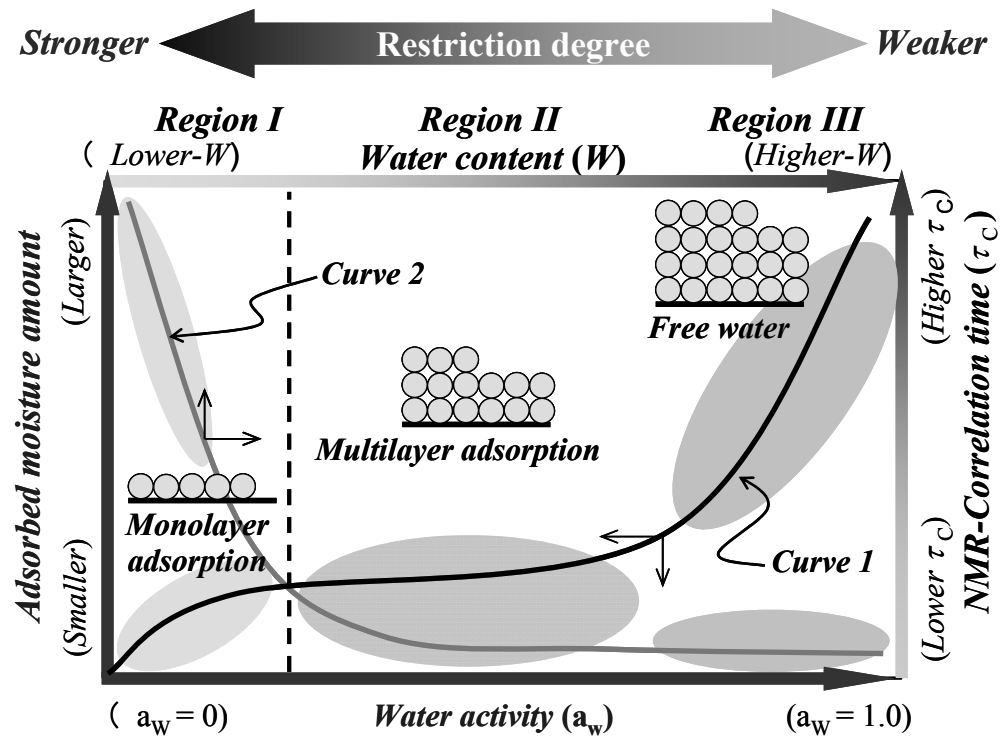

Fig. 2. Classification of the adsorbed water species in the food tissue matrix.

conjunction with the progress of dehydration. In atmospheric conditions, according to the progress of dehydration, the free water species in region III is preferentially removed rather than the two water species in regions I and II.

\subsubsection{Visualization from the chemical engineering technique}

Taking into account the water activity map presented by Labuza et al. (1970) and Schmidt (2004), one may visualize three regions on a water activity space. Fig. 2 shows a schematic explanation of the specified two curves: curve 1 for the water adsorption isotherm of food systems as a function of water activity (the isotherm was divided again into three regions, I, II, and III) and curve 2 for the NMR correlation time $\left(\tau_{\mathrm{C}}\right)$ of water species retained in food as 
a function of water content $\left(W_{0}\right)$. As can be seen from the comparison of the two curves, the water species adsorbed in region I with lower water activity contributes to the higher correlation time $\left(\tau_{\mathrm{C}}\right)$. The higher $\tau_{\mathrm{C}}$ means higher restriction strength derived from the food tissues. The water species adsorbed in the region III with higher water activity, contributing to lower $\tau_{C}$, which means lower restriction strength. These results bring about an inverse relation between the two parameters, $\tau_{\mathrm{C}}$ (curve 2), and the adsorbed water amount (curve 1) as shown in Fig. 2. This relation can be usefully employed in the hybrid technique as is described in upcoming sections.

The three water species distributed in regions I, II, and III presented in Figs. 1 and 2 can be further classified as species $\mathrm{A}_{1}$ and species $\mathrm{A}_{2}$. The water species in regions I and III belong to species $A_{2}$ and species $A_{1}$, respectively. The water species in region II belongs to an intermediate species between species $A_{1}$ and species $A_{2}$. Figure 3 schematically illustrates the water species $A_{1}$ and $A_{2}$ retained in foods as a model description. From the schematic visualization, one may recognize water species $A_{1}$ to be weakly restricted by macromolecules in foods, such as proteins, at greater water content and water species $\mathrm{A}_{2}$ to be strongly restricted due to the progress of dehydration. The space formed due to the dehydration in region III in Fig. 1 would create micropores resulting in higher porosity $(\varepsilon)$ and higher labyrinth factor $(\chi)$ in the food tissue matrix. These micropores would be filled again with water species when re-hydration occurred, indicating a reproducibility of the adsorbed water species as is discussed in upcoming sections (see Fig. 5).
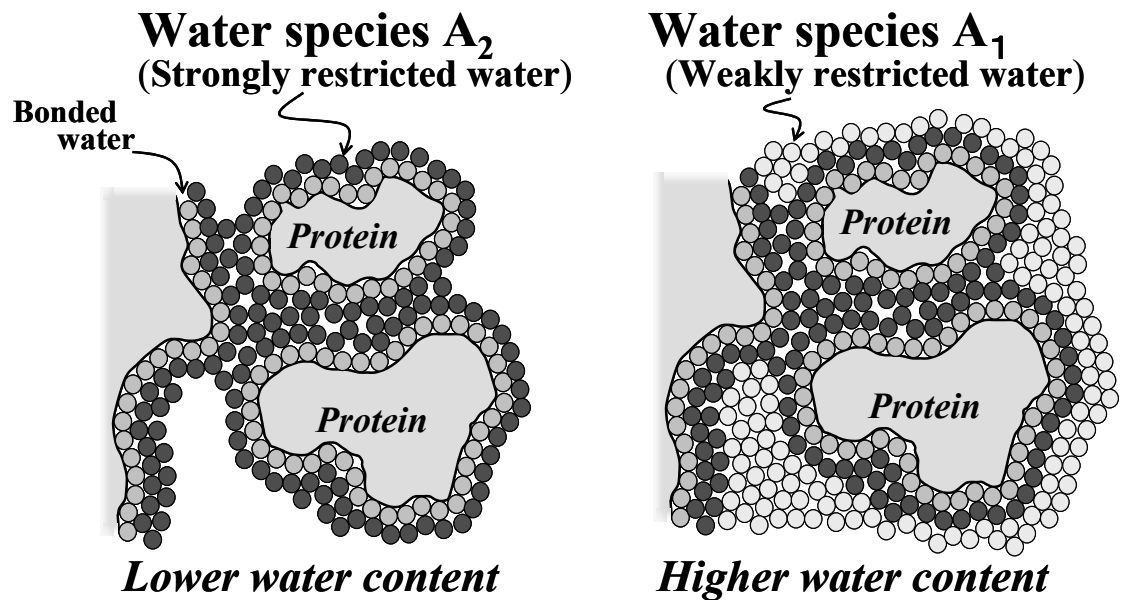

Fig. 3. Schematic explanations of the adsorbed states for water species in foods.

\subsection{Dynamism and reversibility of the water species in foods identified by the proton NMR technique}

The proton NMR spectrum clearly demonstrates the dynamism of water species derived from the dehydration of the sample (Konishi et al., 2010). Figure 4 demonstrates the dynamism of the reduced amount of water species (the dehydration of squid) as a steep reduction of the proton NMR spectra of peak-A. The three peeks, A, B, and C, were identified in our previous work (Konishi et al., 2010) as weakly restricted water, strongly 


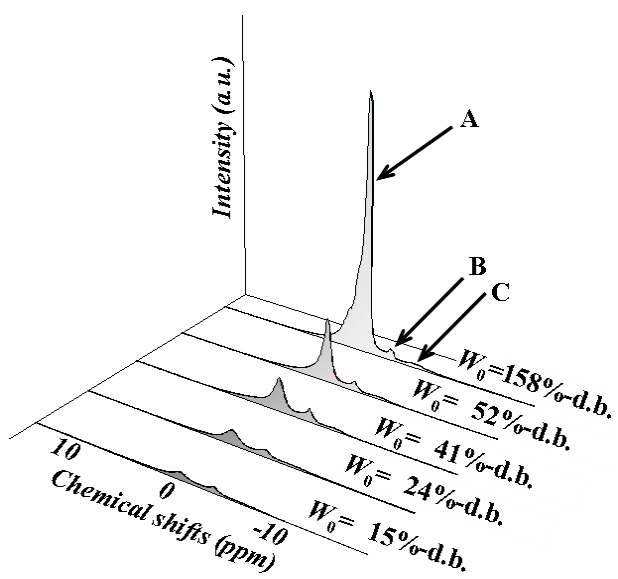

Fig. 4. Dynamic behavior of ${ }^{1} \mathrm{H}-\mathrm{NMR}$ spectra for species $\mathrm{A}, \mathrm{B}$, and $\mathrm{C}$ in the squid muscle in the course of a drying operation.

restricted water, and lipids, respectively. One may recognize the reduction of only peak-A due to dehydration, whereas peaks- $\mathrm{B}$ and $-\mathrm{C}$ gave an identical value indicating that the two species are not influenced by dehydration.

Focusing on the reversibility of peak-A, one can easily recognize the dynamism of proton NMR spectra of water species in the squid, as shown in Figure 5. The strength of peak-A was steeply reduced by dehydration (see curve (1)), and the peak height was restored by re-hydration (see curve (2)), whereas the peaks-B and -C kept the same peak height regardless of dehydration and re-hydration. This reproducibility of peak-A strongly demonstrates the ability

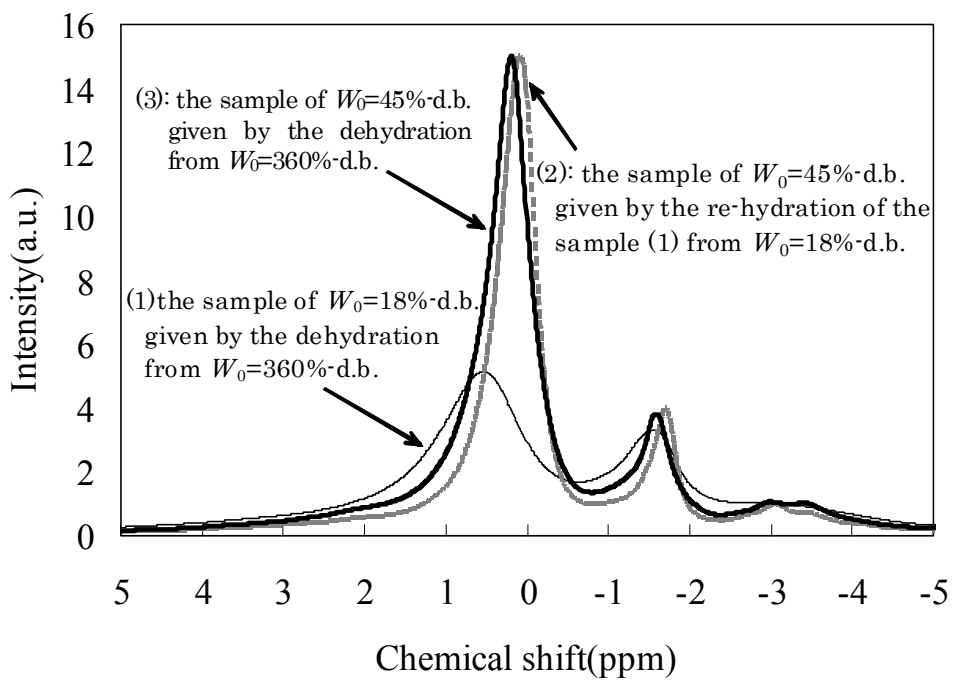

Fig. 5. Reproduced dynamic behavior of ${ }^{1} \mathrm{H}-\mathrm{NMR}$ spectra for species- $\mathrm{A},-\mathrm{B}$ and $-\mathrm{C}$ in the squid muscle. 
of water species $\mathrm{A}_{1}$ and $\mathrm{A}_{2}$ to be reformed in the food tissue matrix through re- hydration. This reversibility is a very important factor for dried food products because, generally speaking, dried foods are frequently re-hydrated before being consumed (dried kelp, dried green onions, and dried noodles, etc.). Exploitation of reversible water species in dried foods could produce the same taste as when the food is freshly prepared. To evaluate the reproducibility of dried food taste, one should focus on $\tau_{C}$ because the $\tau_{C}$ value is closely related to the concentration of seasoning and the kind of food. The reproducibility of $\tau_{C}$ is, therefore, an important factor for taste reproducibility. Figure 6 demonstrates the reproducibility of $\tau_{\mathrm{C}}$ as a function of $W_{0}$. The results show positive reproducibility of $\tau_{\mathrm{C}}$, indicating favorable taste reproducibility in the case of dried squid.

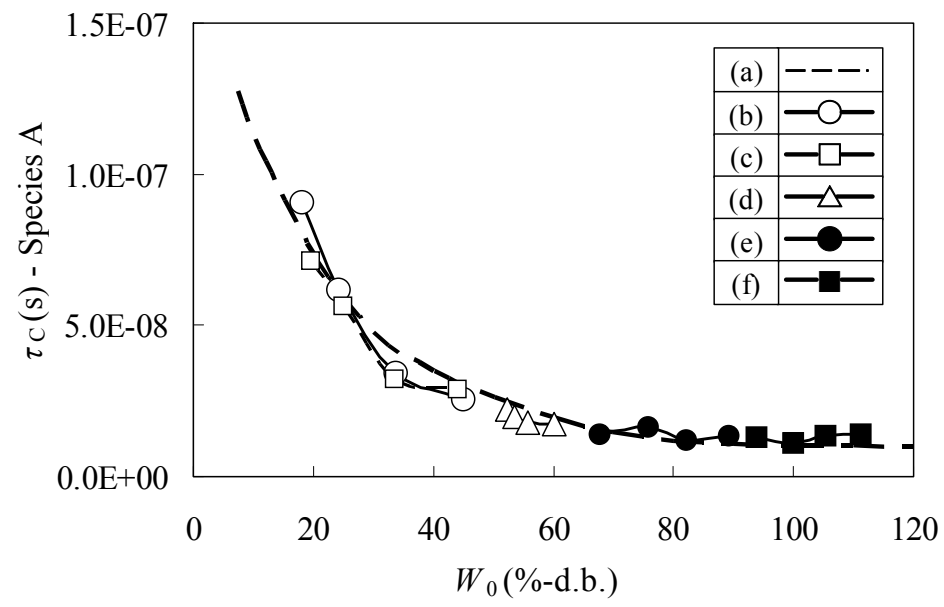

Fig. 6. Reproducibility of $\tau_{C}$ (species A) observed between the dehydration and the waterreadsorption operations for the squid muscle: (a) under the continuous drying operation from $W_{0}=120 \%$-d.b. to $10 \%$-d.b., (b) after the gradual readsorption of water from $W_{0}=18 \%$ d.b. to $W_{0}=45 \%$-d.b., (c) from $W_{0}=20 \%$-d.b. to $W_{0}=44 \%$-d.b., (d) from $W_{0}=50 \%$-d.b. to $W_{0}=60 \%$-d.b., (e) from $W_{0}=68 \%$-d.b. to $W_{0}=89 \%$-d.b., and (f) from $W_{0}=94 \%$-d.b. to $W_{0}=111 \%-d \cdot b$.

\section{Limitations of the proton NMR technique}

To design the food products requested by the markets, the design parameters chosen should be able to clearly discriminate between various kinds of foods depending on requirements. In particular, the water species retained in the foods should be characterized by the kinds of foods and environmental influences such as temperature, atmospheric pressure, water content, etc. Although the proton NMR water species evaluation technique is a useful tool, one should recognize that the method has some difficulty discriminating among water species retained in foods. Figure 7 illustrates the $\tau_{C}$ values as a function of $W_{0}$ for $B_{A}, B_{H}$, and $P_{\mathrm{H}}$. The $\tau_{\mathrm{C}} \sim W_{0}$ curves obtained could not discriminate among the three meats, $\mathrm{B}_{\mathrm{A}}, \mathrm{B}_{\mathrm{H}}$, and $P_{H}$ (Konishi and Kobayashi, 2009), even though the water species $A_{1}$ and $A_{2}$ are roughly distinguished at the critical point of $\tau_{C}=C \tau_{C}=10^{-8} \mathrm{~s}$. This unclear discrimination between the three curves can be understood as a limitation of the proton NMR technique. 


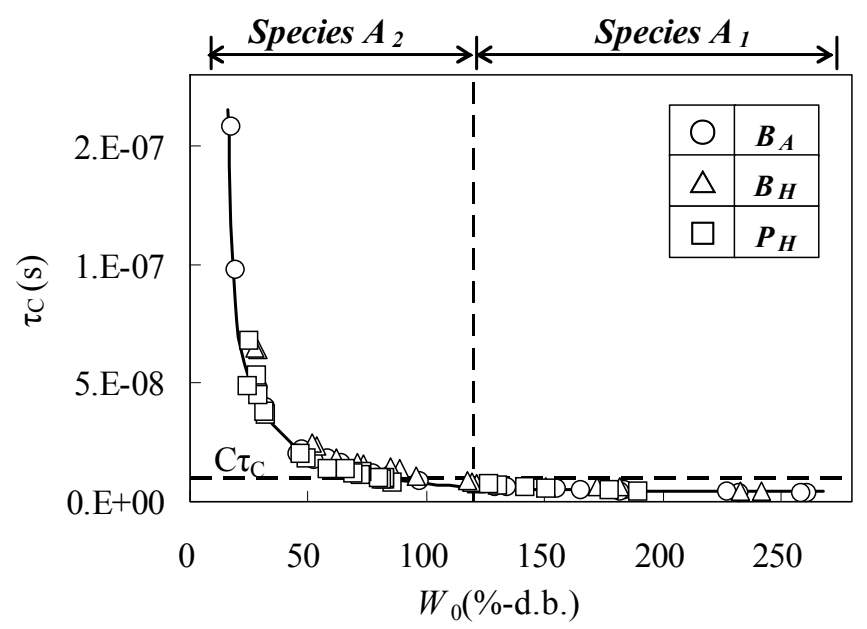

Fig. 7. $\tau_{\mathrm{C}}$ as a function of $W_{0}$ for $\mathrm{B}_{\mathrm{A}}, \mathrm{B}_{\mathrm{H}}$, and $\mathrm{P}_{\mathrm{H}}$.

Figure 8 illustrates $\tau_{\mathrm{C}}$ as a function of water content $\left(W_{0}\right)$ of the 12 jerkies and the $\mathrm{P}_{\mathrm{H}}$. The solid line for $P_{\mathrm{H}}$ indicated a steep increase with decreasing $W_{0}$, between the values of $\tau_{\mathrm{C}}=$ $1.0 \times 10^{-8} \mathrm{~S}$ and $\tau_{\mathrm{C}}=1.1 \times 10^{-7} \mathrm{~s}$. Since $\tau_{\mathrm{C}}$ indicates rotation time of the water species, the steep increase of $\tau_{\mathrm{C}}$ demonstrates that the restriction strength of the water species in this region increases markedly upon dehydration from $W_{0}=120$ to $20 \%$-d.b. Similar results were also obtained for the beef (Konishi and Kobayashi, 2009). The $\tau_{C}$ for the jerkies, on the other hand, fell around the solid line of $\mathrm{P}_{\mathrm{H}}$. From these results, one can recognize that it is difficult to distinguish among the three $\tau_{\mathrm{C}}-W_{0}$ curves for the pork jerkies, beef jerkies, and $\mathrm{P}_{\mathrm{H}}$, indicating again a limitation of the proton NMR technique.

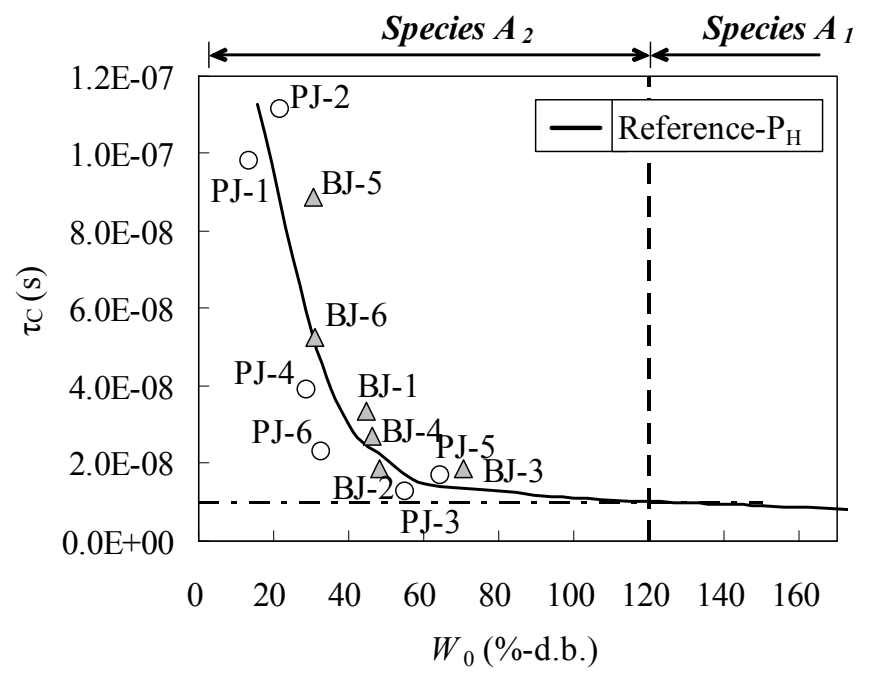

Fig. 8. тc as a function of $W_{0}$ for the pork and beef jerkies (open circle and closed triangle) and the pork (solid line). 


\section{Limitation of the chemical engineering technique}

\subsection{Unclear discrimination of water activity in foods in the chemical engineering technique}

Water activity $\left(a_{w}\right)$ has conveniently been used to design food products because of the ease of evaluating the variable using the chemical engineering technique (Fennema, 1976). Figure 9 illustrates $\mathrm{a}_{\mathrm{w}}$ as a function of $W_{0}$ for the squid and the salmon. As can be seen from the comparison between the two curves, an identical curve was obtained without detecting any difference between the squid and the salmon. This result strongly indicates a limitation of the chemical engineering technique. To develop a new food product, one should choose another parameter for discriminating among products. To address this issue, a computer simulation method for developing new food design parameters is proposed in the next section.

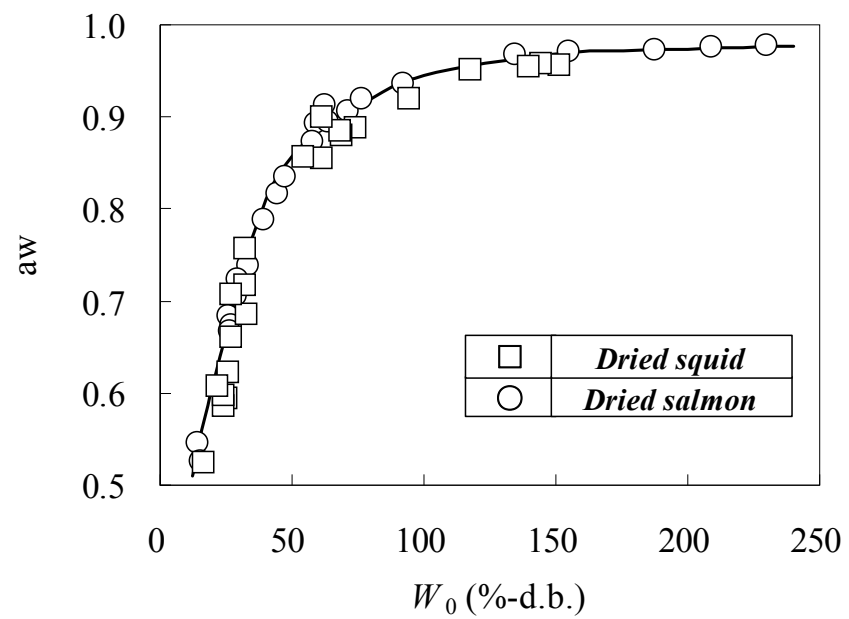

Fig. 9. $a_{w}$ as a function of $W_{0}$ for the salmon and squid.

\subsection{Ambiguous physical meaning of the chemical engineering parameters derived from a computer simulation for the dehydration dynamism of salmon}

\subsubsection{Dehydration dynamism of the water species in the salmon}

To characterize the water species retained in the salmon, dehydration response curves could effectively be employed. Figure 10 illustrates the dehydration response curves as a function of the water content of the salmon. The five samples of $W_{0}=54,99,144,200$, and 252\%-d.b. were prepared from a sample of $W_{0}=342 \%$-d.b., and each of the samples was treated by a PUP-operation (poultice up: the samples were stored in a dark room at $T=2^{\circ} \mathrm{C}$ for $24 \mathrm{~h}$ before use; this operation was conducted to provide homogeneity of water distribution in the sample). The PUP operation contributes to the stepwise increase of the dehydration rate, as shown in Figure 11, by the curves of $b^{\prime} \sim f^{\prime}$. Focusing on the five points of $b \sim f$ on the dehydration curve of $W_{0}=342 \%$-d.b. in Fig. 11(A), the dehydration rates of the five samples clearly demonstrate a stepwise increase, as shown in Fig. 11(B), by the curves of $b^{\prime} \sim f^{\prime}$ due to PUP operation. One can recognize that curves $b^{\prime} \sim f^{\prime}$ demonstrate a monotonous decay 


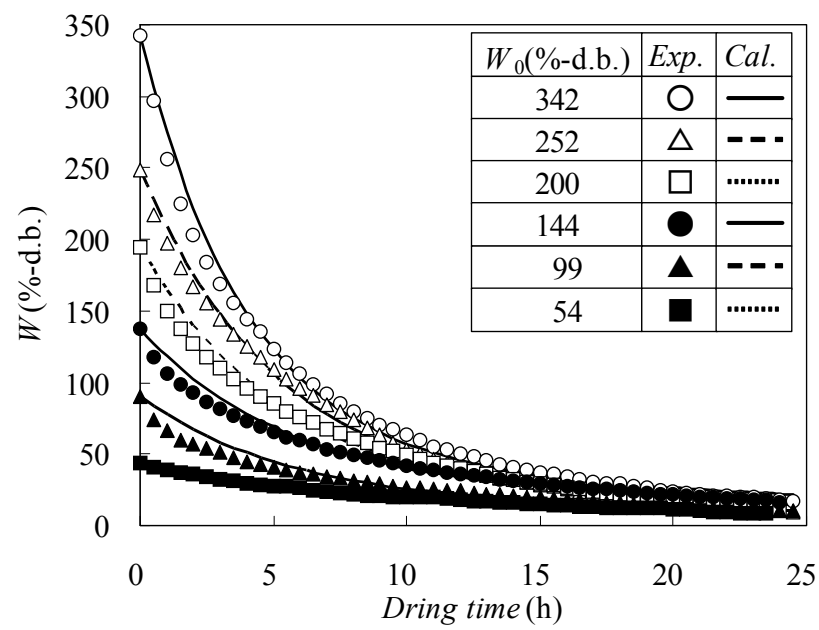

Fig. 10. Dehydration response curves of the salmon $\left(T_{D}=45^{\circ} \mathrm{C}\right)$.

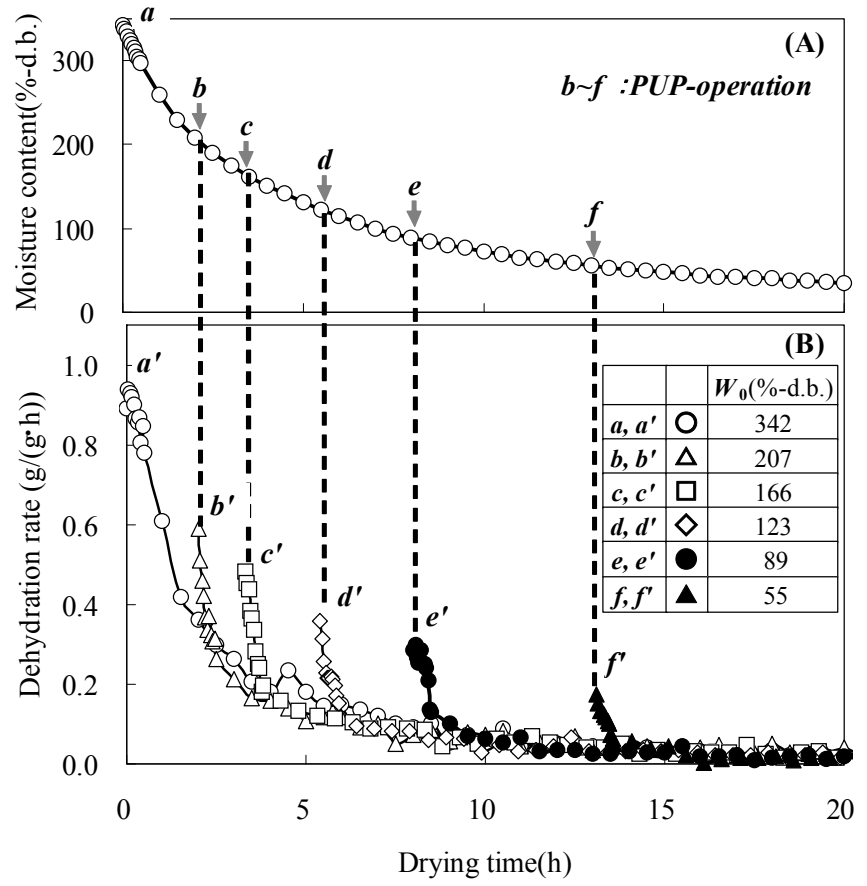

Fig. 11. Acceleration behavior of dehydration rate derived from the PUP operation for the salmon $\left(T_{\mathrm{D}}=45^{\circ} \mathrm{C}\right)$.

curve reaching finally to the curve of $a^{\prime}$ with an increase in the elapsed time. Using the dehydration rates obtained, the effective diffusivity of the water species, $D e$, can be evaluated as a function of $W_{0}$ by applying Equation (1). 


\subsubsection{Physicochemical mobility $(D e)$ of the water species}

One can recognize the $D e$ value as a physicochemical mobility of the water species retained in the foods. Figure 12 illustrates $D e$ for the salmon as a function of $W_{0}$ and temperature. Although the data are widely scattered, one can roughly recognize two different water species (species $A_{1}$ and $A_{2}$ ) formed in the salmon, depending on the values of $W_{0}$. The two water species were divided at about $W_{0}=120 \%$-d.b., indicating an identical $D e$ for the water species $\mathrm{A}_{1}$ region between $W_{0}=120$ and $360 \%$-d.b. and a gradual decrease of De for the water species $A_{2}$ region with decreasing $W_{0}$ at $35 \sim 55^{\circ} \mathrm{C}$. Using a rough evaluation of $D e$ obtained at the three temperatures, one would roughly construct the Arrhenius plots as shown in Figure 13. The slopes of the straight lines seem to give different activation energies depending on the water content of the samples.

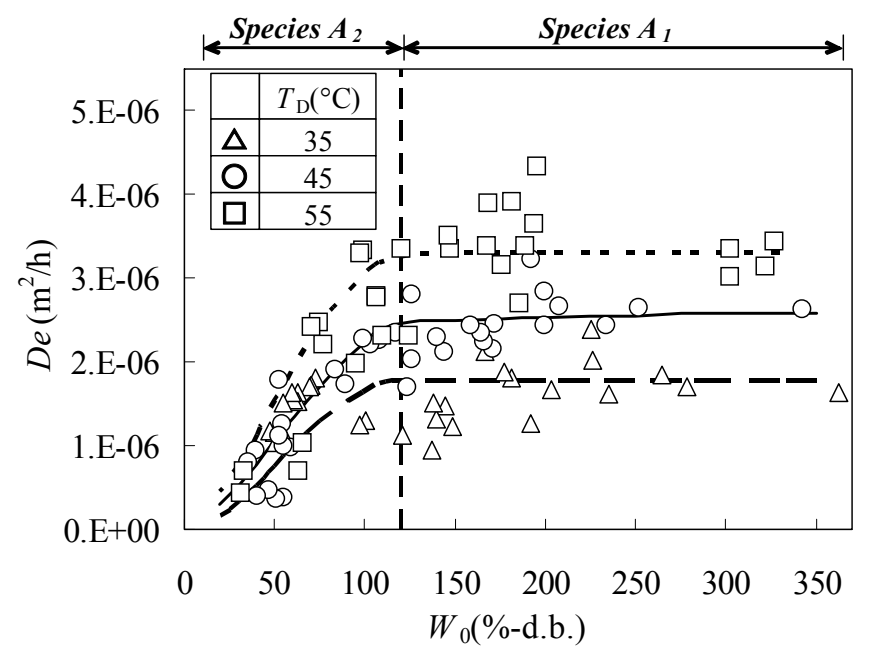

Fig. 12. De as a function of $W_{0}$ in the salmon.

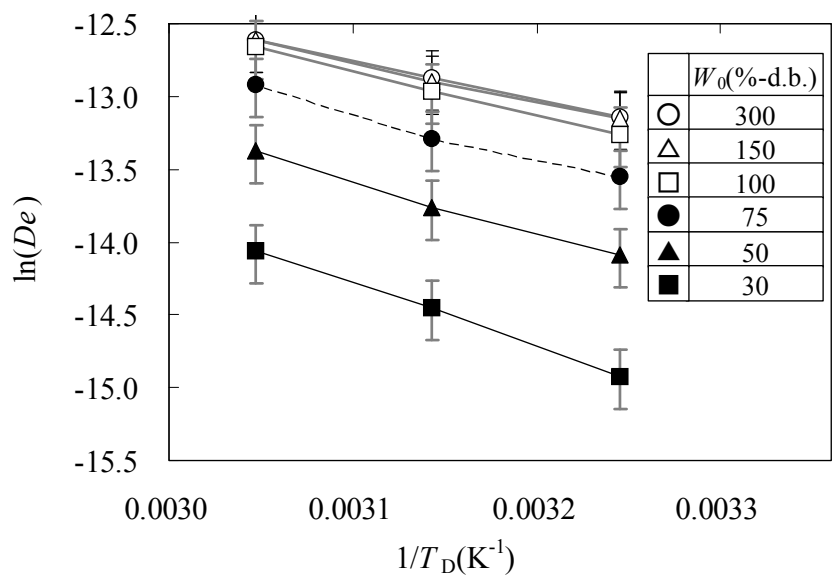

Fig. 13. Arrhenius plots of De for the salmon. 
Figure 14 demonstrates $E_{\mathrm{D}}$ as a function of $W_{0}$. The activation energy obtained, the $E_{\mathrm{D}}$ values, demonstrates again two water species, $\mathrm{A}_{1}$ and $\mathrm{A}_{2}$, divided at $W_{0}=120 \%$-d.b. $E_{\mathrm{D}}$ in the water species $A_{1}$ region gave an identical value of $22( \pm 4) \mathrm{kJ} / \mathrm{mol}$ and a gradual increase from 20 to $38( \pm 8) \mathrm{kJ} / \mathrm{mol}$ with decreasing $W_{0}$. Taking into account the restriction of water species growth that accompanies increased dehydration, one can observe evidence of the activation energy growth (indicating a difficulty of the molecular diffusion of water species in the food tissue matrix due to the growth of the restriction strength) as a result of the decrease of water species mobility $(D e)$.

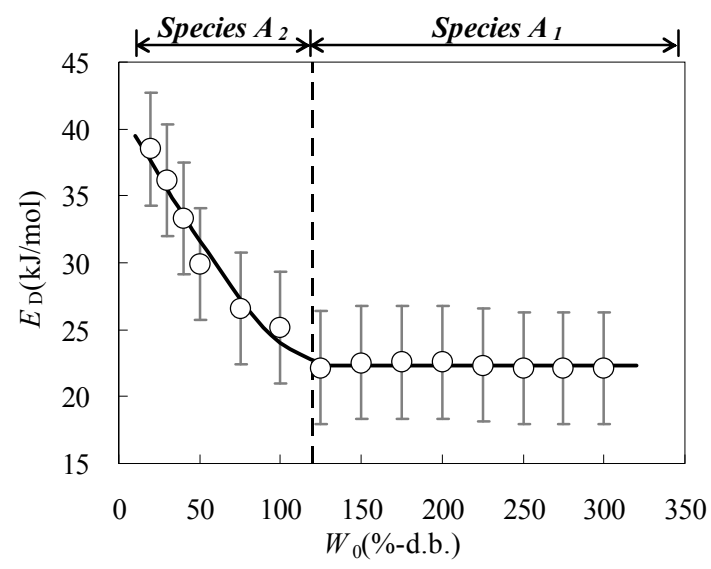

Fig. 14. $E_{\mathrm{D}}$ as a function of $W_{0}$ for the salmon.

As for a reason that the activation energy was drastically changed at $W_{0}=120 \%$-d.b., it can be attributed to a change in the physical structure of the food tissue matrix due to progressive dehydration. The value of $W_{0}=120 \%$-d.b. corresponds exactly to the critical value of $\tau_{C}\left(C \tau_{C}=10^{-8} \mathrm{~s}\right)$, at which water species $A_{1}$ and $A_{2}$ were divided according to their restriction strength, and the pre-exponential factor $\left(\mathrm{PF}=\delta \cdot D_{0}\right)$ of De showed steep growth with decreasing $W_{0}$ (as will be discussed in the upcoming section, see Fig. 16). The steep growth of PF resulted from the drastic change in the porosity and labyrinth factor of the salmon at $W_{0}=120 \%$-d.b. accompanied by the gradual reduction of De decreasing $W_{0}$.

\subsubsection{Water tank model for the computer simulation of the dehydration response curves}

The transient response curves of dehydration in the drying operation of foods have been simulated using various mathematical models (Chhinnan, 1984; Madamba et al., 1996; Thompson et al., 1968; Noomhorm and Verma, 1986). In the present study, the dehydration response curves of the salmon presented in Fig. 10 are simulated using a water tank model as a first approximation. The water species retained in the sample are portioned to two different water tanks and the two tanks are respectively filled by the two different water species, $A_{1}$ (weakly restricted water species) and $A_{2}$ (strongly restricted water species), as shown in Figure 15 (Konishi et al., 2001). During the drying operation, the two water species in the tanks are simultaneously drained by regulating the two valves as mass transfer coefficient, $k_{\mathrm{W}}\left(\mathrm{h}^{-1}\right)$ and $k_{\mathrm{S}}\left(\mathrm{h}^{-1}\right)$. 


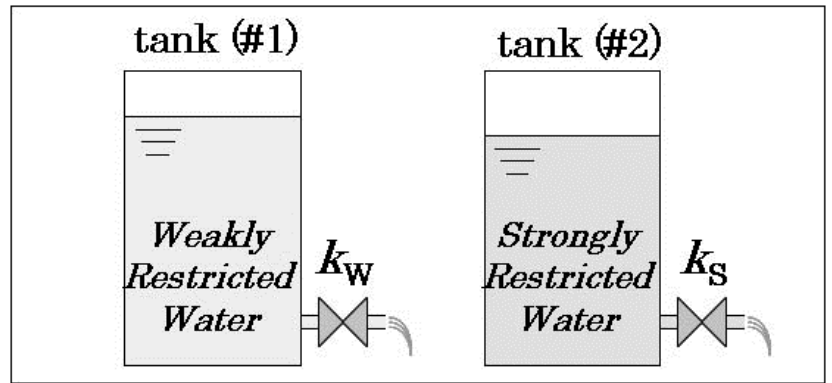

Fig. 15. Schematic explanation of the water tank model proposed as a dehydration of food.

On the material balance equation in the course of the dehydration operation presented in Fig. 10, the water content $(W)$, presented as a perpendicular axis of Fig. 10, can be replaced by the water ratio, $W_{\mathrm{R}}=(W-W e) /\left(W_{\mathrm{D}}-W e\right)$, where $W e$ is the equilibrium water content $(\%-$ d.b.) and $W_{\mathrm{D}}$ is the initial water content of the sample. The dynamism of $W_{R}$ for the two tanks is expressed by Equation (4).

$$
\begin{gathered}
\left(-\frac{d W_{R I}}{d t}\right)=\left(-\frac{d W_{R w}}{d t}\right)+\left(-\frac{d W_{R s}}{d t}\right) \\
-\frac{d W_{R w}}{d t}=k_{w} \cdot W_{R w} \\
-\frac{d W_{R s}}{d t}=k_{s} \cdot W_{R s},
\end{gathered}
$$

where $W_{\mathrm{RW}}$ is the ratio of the weakly restricted water species $\left(=\left(W_{\mathrm{W}}-W e\right) /\left(W-W_{\mathrm{D}}\right)\right), W_{\mathrm{RS}}$ is the ratio of the strongly restricted water species $\left(=\left(W_{\mathrm{S}}-W e\right) /\left(W-W_{\mathrm{D}}\right)\right), W_{\mathrm{W}}$ is the amount of weakly restricted water species (\%-d.b.), and $W_{\mathrm{S}}$ is the amount of strongly restricted water species (\%-d.b.).

The differential equation (4) is easily solved and expressed by Equation (7).

$$
\begin{gathered}
W_{R}=\frac{W-W e}{W_{D}-W e}=W_{R 1} \exp \left[k_{s} \exp \left(\frac{-E_{\mathrm{D}}}{R \cdot\left(T_{\mathrm{D}}+273\right)}\right) \cdot t\right] \\
+W_{R 2} \exp \left[k_{w} \exp \left(\frac{-E_{\mathrm{D}}}{R \cdot\left(T_{\mathrm{D}}+273\right)}\right) \cdot t\right] \\
k_{s}=\beta_{1} \cdot D e^{0} \\
k_{w}=\beta_{2} \cdot D e^{0}
\end{gathered}
$$

where $W_{\mathrm{R} 1}$ and $W_{\mathrm{R} 2}$ are a proportion of the strongly restricted water amount and the weakly restricted water amount, respectively, and $k_{S}\left(\mathrm{~h}^{-1}\right)$ and $k_{\mathrm{W}}\left(\mathrm{h}^{-1}\right)$ are the mass transfer coefficient of the strongly restricted water species and of the weakly restricted water species, 
respectively. $D e^{0}\left(=\delta \cdot D_{0}\right)$ is the pre-exponential factor of $D e$, and $\beta_{1}$ and $\beta_{2}$ are the constants evaluated by a curve fitting simulation between the experimental and the calculated curves as shown in Fig. 10. The curve fitting obtained showed favorable agreement with the experimental dehydration curves as shown in Fig. 10 by solid curves.

\subsubsection{Discrimination of water species $A_{1}$ and $A_{2}$ due to the pre-exponential factor $\left(D e^{0}\right)$ of $\mathrm{De}$}

The pre-exponential factor, $D e^{0}$, can easily be evaluated by the extrapolation of the Arrhenius plot lines against the perpendicular axes in Fig. 13. Figure 16(A) illustrates $D e^{0}$ as a function of $W$. The $D e^{0}$ values obtained were of identical value regardless of $W$ in the water species $A_{1}$ region, whereas in the water species $A_{2}$ region, there was a steep increase with decreasing $W_{0}$.

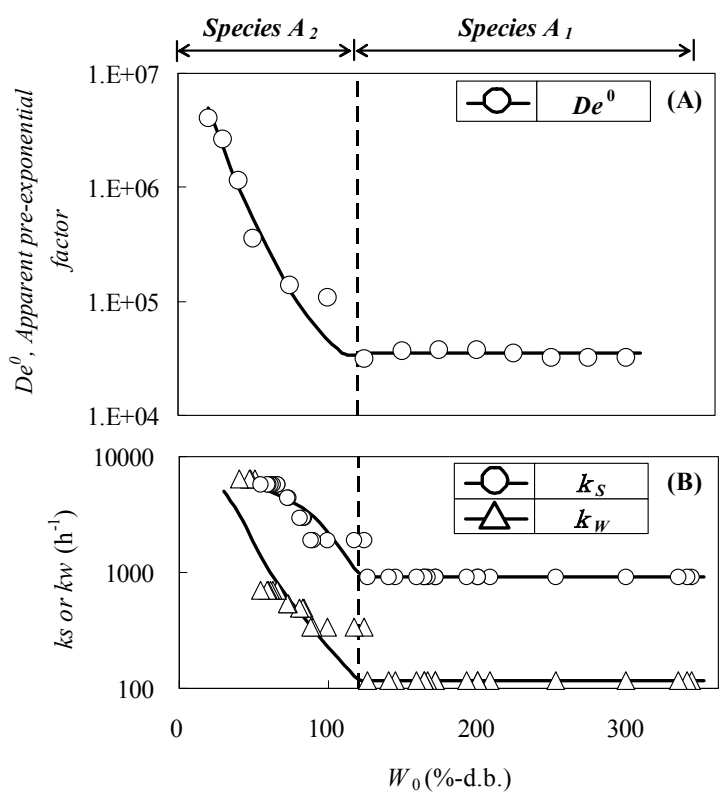

Fig. 16. Pre-exponential factor $\left(D e^{0}\right)$ and the dehydration parameters for the computer simulation $\left(k_{\mathrm{S}}, k_{\mathrm{W}}\right)$ as a function of $W_{0}\left(T_{\mathrm{D}}=45^{\circ} \mathrm{C}\right)$ for the salmon.

Figure 16(B) illustrates $k_{\mathrm{S}}$ and $k_{\mathrm{W}}$ as a function of $W_{0}$. The two values show tendencies similar to $D e^{0}$ even though they can be evaluated by the computer simulation. Comparing the two values between $k_{\mathrm{S}}$ (or $k_{\mathrm{W}}$ ) and $D e^{0}$, one can generate a linear relation between the two values as shown in Figure 17. The parameters of $k_{\mathrm{S}}$ and $k_{\mathrm{W}}$ roughly demonstrate the equations of $k_{\mathrm{S}}=0.025( \pm 0.008) D e^{0}$ and $k_{\mathrm{W}}=0.007( \pm 0.004) D e^{0}$. Using Equations (8) and (9), one may evaluate $\beta_{1}=0.025( \pm 0.008)$ and $\beta_{2}=0.007( \pm 0.004)$. Concerning the physical meaning of $\beta_{1}$ and $\beta_{2}$, since the two parameters were evaluated by the computer fitting simulation, they seem to be meaningless. This evidence indicates a disadvantage of the chemical engineering technique, even though the linear relation between $k_{\mathrm{S}}$ (or $k_{\mathrm{W}}$ ) and $D e^{0}$ would cause the presumption of a relationship between the two parameters. 


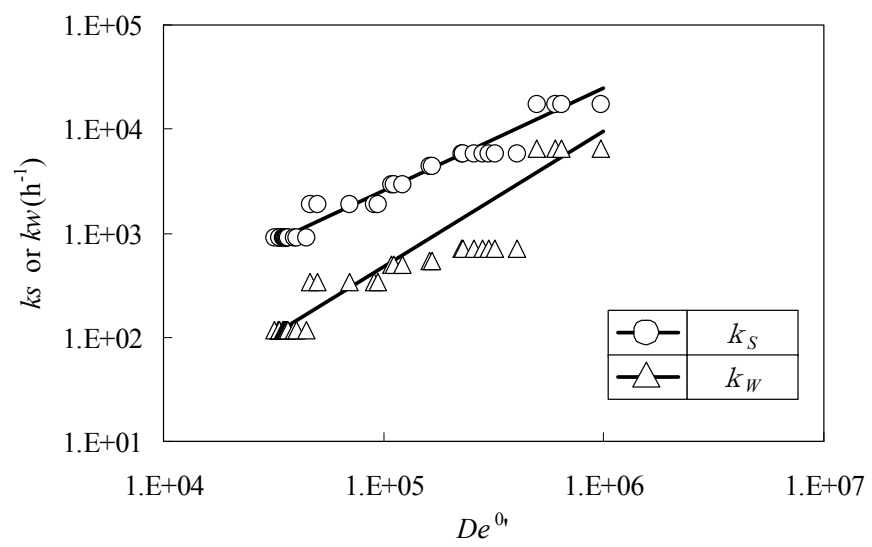

Fig. 17. Dehydration parameters ( $k s$ and $k w)$ as a function of pre-exponential factor $\left(D e^{0}\right)\left(T_{\mathrm{D}}=45^{\circ} \mathrm{C}\right)$ for the salmon.

\section{Advantages derived from the hybrid technique}

\subsection{Visualized correlation between molecular mobility $\left(\tau_{c}\right)$ and physicochemical mobility $(D e)$}

Physicochemical mobility, De, which is evaluated by the chemical engineering technique (Fig. 12), and molecular mobility, $\tau_{C}$, which is evaluated by the proton NMR technique (Fig. 8), are important parameters for characterizing the water species retained in foods as the diffusion rate in the three dimensional space of the food tissue matrix and as the rotation time of water molecules, respectively. The two parameters $\left(D e\right.$ and $\left.\tau_{\mathrm{C}}\right)$ for the pork meat $\left(\mathrm{P}_{\mathrm{H}}\right)$ and 12 jerkies are interestingly related, as shown in Figure 18. This clearly shows an advantage of the hybrid technique. $D e$ for $P_{\mathrm{H}}$ demonstrates a drastic change at $\tau_{\mathrm{C}}=10^{-8} \mathrm{~s}$,

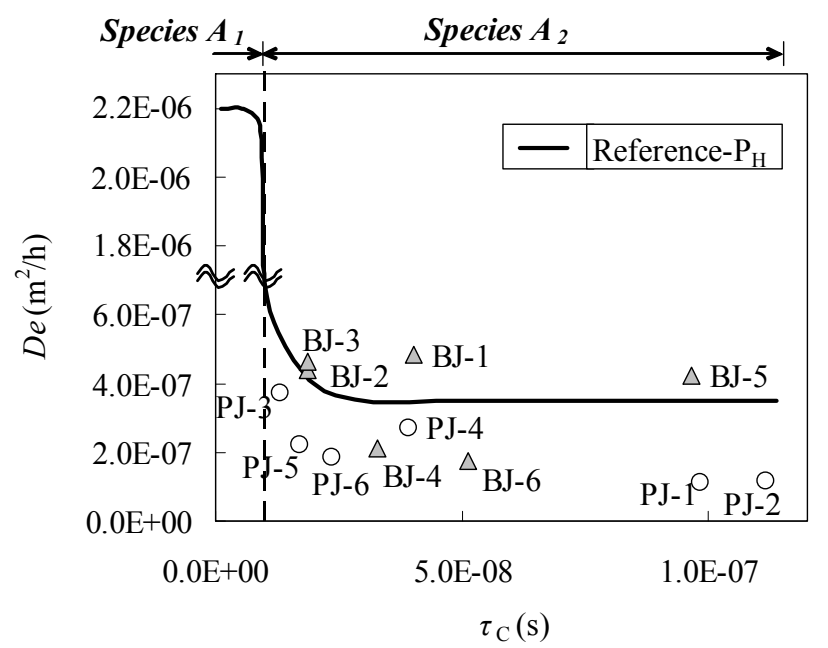

Fig. 18. De as a function of $\tau_{\mathrm{C}}$ for jerkies and $\mathrm{P}_{\mathrm{H}}$. 
indicating an identical $D e=2.2( \pm 0.2) \times 10^{-6} \mathrm{~m}^{2} / \mathrm{h}$ in the species $\mathrm{A}_{1}$ region and $D e=3.5( \pm 1.0)$ $\times 10^{-7} \mathrm{~m}^{2} / \mathrm{h}$ in the water species $A_{2}$ region. All the $D e$ values for the commercial jerkies are distributed in the water species $A_{2}$ region, indicating an identical $D e=3.0( \pm 1.8) \times 10^{-7} \mathrm{~m}^{2} / \mathrm{h}$, which, even though the data are widely scattered, is the same as $P_{\mathrm{H}}$. Regarding the jerky data, although all the samples distributed in the market commonly use the water species $A_{2}$ not $A_{1}$ and the effective diffusivity, $D e$, falling in the range of $1.0 \sim 5.0 \times 10^{-7} \mathrm{~m}^{2} / \mathrm{h}, \tau_{\mathrm{C}}$ is widely distributed in the range of $10^{-8} \sim 1.1 \times 10^{-7} \mathrm{~s}$. Since each of the jerkies used in this study has own taste different from other, the wide distribution of $\tau_{C}$ has an important meaning in developing different tastes in jerky. This idea is also supported in an upcoming section.

\subsection{Clear discrimination of the two water species due to diffusivity (De)}

As has been demonstrated in Fig. 12, the De $W_{0}$ plots could not clearly discriminate the water species $A_{1}$ and $A_{2}$. The De $\tau_{C}$ plots derived from the hybrid technique, on the other hand, are conveniently able to visualize the discrimination between beef and pork and the two water species, $A_{1}$ and $A_{2}$, as shown in Figure 19. In particular, the boundary of the two water species is clearly recognized as $C_{\tau_{C}}=10^{-8} \mathrm{~s}$, indicating an advantage of the hybrid technique. Focusing on the behavior of $\mathrm{B}_{\mathrm{A}}, \mathrm{B}_{\mathrm{H}}$, and $\mathrm{P}_{\mathrm{H}}$, the De values gave a constant value in the two water species regions: in the $A_{1}$ region, as $3.1( \pm 0.5) \times 10^{-6}, 4.7( \pm 0.1) \times 10^{-6}$, and $2.2( \pm 0.3) \times 10^{-6} \mathrm{~m}^{2} / \mathrm{h}$, respectively; in the $A_{2}$ region, as $1.8( \pm 0.5) \times 10^{-6}, 2.0( \pm 0.4) \times 10^{-6}$, and $7.0( \pm 1.0) \times 10^{-7} \mathrm{~m}^{2} / \mathrm{h}$, respectively, even though $\tau_{C}$ is significantly changed from $10^{-8}$ to $4.5 \times 10^{-8} \mathrm{~s}$. These results suggest the water species $\mathrm{A}_{2}$ has the interesting characteristic of being able to make a wide shift of the molecular mobility, $\tau_{C}$, without changing in the $D e$ values. This result indicates that, by changing the value of $\tau_{C}$ as a design parameter for food products, the character of various meats can be significantly altered. The hardness of various meats and salmon, for example, can also be controlled by a change in $\tau_{C}$, as shown in the next section.

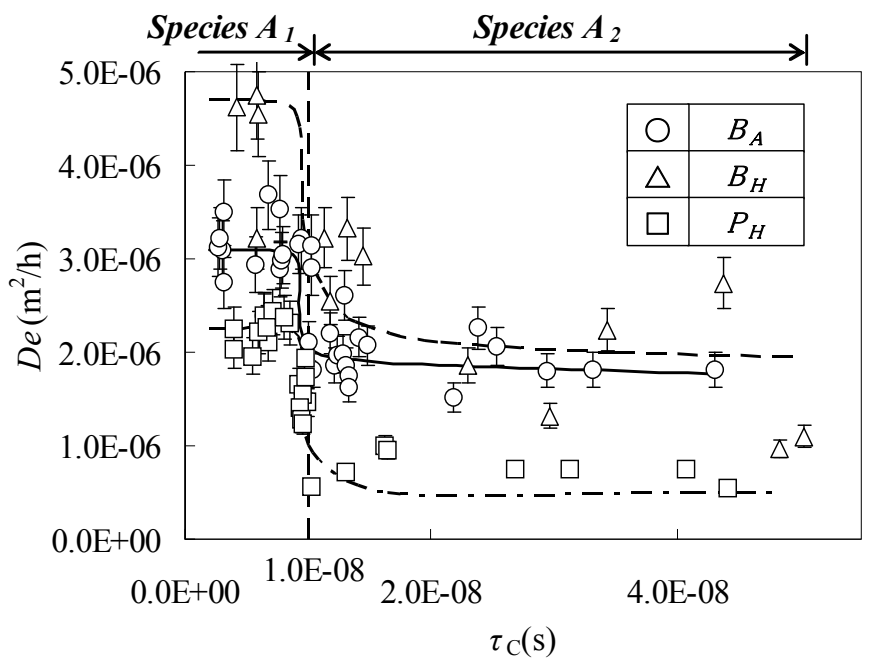

Fig. 19. Comparing behavior of De among $\mathrm{B}_{\mathrm{A}}, \mathrm{B}_{\mathrm{H}}$, and $\mathrm{P}_{\mathrm{H}}$ as a function of $\tau_{\mathrm{C}}$ at $70^{\circ} \mathrm{C}$. 


\subsection{Clear discrimination of the two water species by hardness}

Figure 20 demonstrates the hardness of $\mathrm{B}_{\mathrm{A}}, \mathrm{B}_{\mathrm{H}}, \mathrm{P}_{\mathrm{H}}$, and salmon as a function of $\tau_{\mathrm{C}}$. The hardness of all the samples shows a drastic increase at $C \tau_{C}=10^{-8} \mathrm{~s}$ with increasing $\tau_{C}$ in the water species $A_{2}$ region. This clear discrimination between the water species $A_{1}$ and $A_{2}$ is an advantage of the hybrid technique. One may recognize that the $N_{\mathrm{P}}$ value in the water species $\mathrm{A}_{1}$ region commonly showed $1.0( \pm 0.5) \times 10^{6} \mathrm{~N} / \mathrm{m}^{2}$ regardless of $\tau_{C}$ in all the samples, whereas in the water species $A_{2}$ region and at the range of $\tau_{C}=3 \times 10^{-8} \sim 6 \times 10^{-8} \mathrm{~s}$, it varied widely depending on the samples, as with $N_{\mathrm{P}}=1.5 \times 10^{7}$ for $\mathrm{B}_{\mathrm{A}}, 1.3 \times 10^{7}$ for $\mathrm{B}_{\mathrm{H}}$, and $1 \times 10^{7}$ $\mathrm{N} / \mathrm{m}^{2}$ for $\mathrm{P}_{\mathrm{H}}$ at $\tau_{\mathrm{C}}=5.0 \times 10^{-8} \mathrm{~s}$. From these results, one can recognize that it is possible to design food products with different $N_{P}$ values without changing the $\tau_{C}$ values, and it's possible to design products with different $\tau_{C}$ values without changing the $N_{P}$ values. Keeping $N_{P}=1.0 \times 10^{7} \mathrm{~N} / \mathrm{m}^{2}$, for example, one can have different $\tau_{C}$ values such as $\tau_{C}=$ $2.9 \times 10^{-8} \mathrm{~s}$ for $\mathrm{B}_{\mathrm{A}}, \tau_{\mathrm{C}}=3.5 \times 10^{-8} \mathrm{~s}$ for $\mathrm{B}_{\mathrm{H}}$, and $\tau_{\mathrm{C}}=4.8 \times 10^{-8} \mathrm{~s}$ for $\mathrm{P}_{\mathrm{H}}$. Although the physical meaning of this $\tau_{C}$ value shift is still unclear, it can be attributed to the taste difference between $\mathrm{B}_{\mathrm{A}}, \mathrm{B}_{\mathrm{H}}$, and $\mathrm{P}_{\mathrm{H}}$ because concrete evidence that the $\tau_{C}$ value changes depending on the kind of food, the concentration of seasonings, and the kind of seasonings has been obtained. Details of these results will be reported in an upcoming work (Konishi and Kobayashi, 2011).

The visualization of $N_{P} \sim \tau_{C}$ exhibited in Fig. 20 clearly demonstrates the hybrid technique as a useful tool for discriminating between the two water species and among the kinds of food.

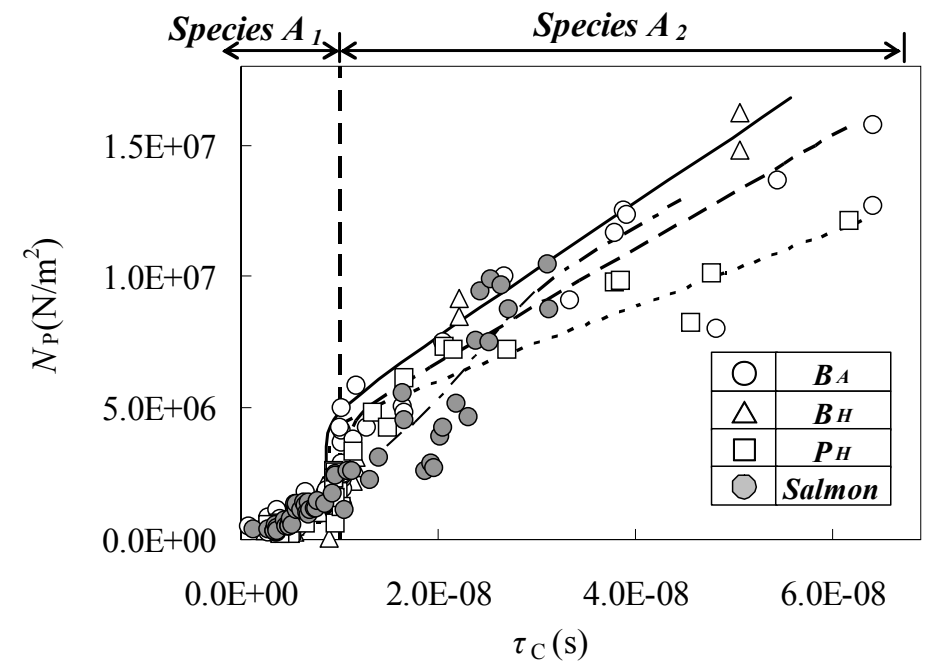

Fig. 20. Comparing behavior of $N_{\mathrm{P}}$ as a function of $\tau_{\mathrm{C}}$ between $\mathrm{B}_{\mathrm{A}}, \mathrm{B}_{\mathrm{H}}$, and $\mathrm{P}_{\mathrm{H}}$ at $50^{\circ} \mathrm{C}$.

\subsection{Physical meaning of $C_{\tau c}=10^{-8} \mathrm{~s}$ derived from the pre-exponential factor $\left(D e^{0}\right)$ of $D e$}

Focusing on the boundary $\left(C_{\tau_{C}}=10^{-8} \mathrm{~s}\right)$ between water species $A_{1}$ and $A_{2}$, one may be interested in what is happening in the food tissue matrix at the $C_{\tau_{C}}=10^{-8} \mathrm{~s}$. The information for the food tissue matrix can be obtained from Equation (2), and the equation is rewritten by Equation (10). The pre-exponential factor $\left(\delta D_{0}\right)$ of Equation (10) consists of a function of $\varepsilon$, 
$\chi$, and $\Delta$ S. Since the $\delta D_{0}$ value can be evaluated from the extrapolation of the Arrhenius plots against the perpendicular axes in Fig. 13, those evaluated for $\mathrm{B}_{\mathrm{A}}, \mathrm{B}_{\mathrm{H}}$, and $\mathrm{P}_{\mathrm{H}}$ can be plotted as a function of $\tau_{C}$, as shown in Figure 21. Three $\delta D_{0}$ curves obtained demonstrate a steep decay at the $C \tau_{C}=10^{-8} \mathrm{~s}$. Based on the rough evaluation of the steep decay for the three curves to be $1 / 30 \sim 1 / 150$, the reduction of the $\delta D_{0}$ values should be attributed to a simultaneous change in the $\varepsilon$ value, which becomes smaller while the $\chi$ value becomes larger and the $\Delta S$ value becomes smaller because of the steep change in the physical structure of the $\mathrm{B}_{\mathrm{A}}, \mathrm{B}_{\mathrm{H}}$, and $\mathrm{P}_{\mathrm{H}}$ 's tissue matrix at the $\mathrm{C}_{\tau_{\mathrm{C}}}=10^{-8} \mathrm{~s}$ derived from dehydration.

$$
D e=\delta D_{0} \cdot \exp \left(\frac{-E_{\mathrm{D}}}{R \cdot\left(T_{\mathrm{D}}+273\right)}\right)=\left(\frac{\varepsilon}{\chi}\right) \cdot\left(\frac{k \cdot\left(T_{\mathrm{D}}+273\right)}{h}\right)\left[\exp \left(\frac{\Delta S}{R}\right)\right] \cdot \exp \left(\frac{-E_{\mathrm{D}}}{R \cdot\left(T_{\mathrm{D}}+273\right)}\right)
$$

where $k$ is Boltzmann constant, $h$ is Planck constant, $\delta(=\varepsilon / \chi)$ is diffusibility, $\varepsilon$ is porosity, $\chi$ is labyrinth factor, and $\Delta S$ is activation entropy.

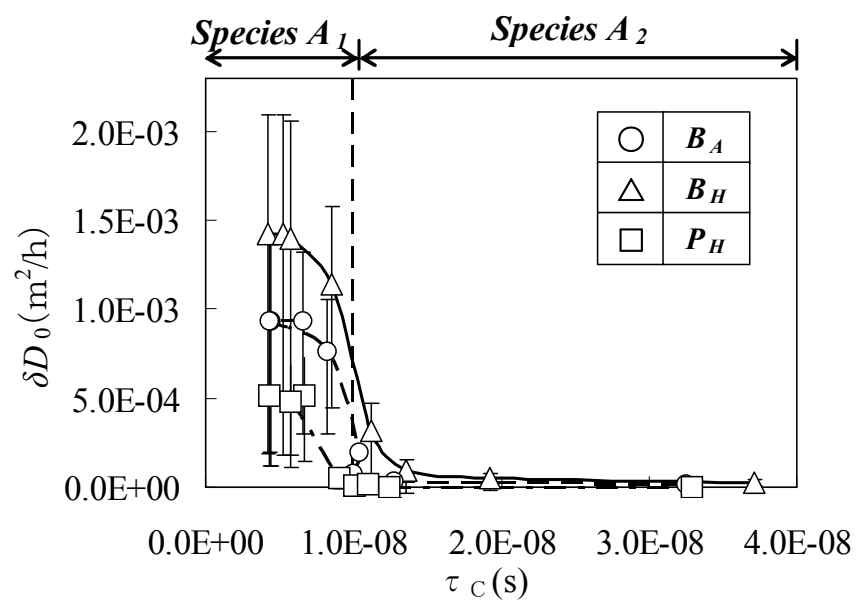

Fig. 21. Comparing behavior of the pre-exponential factor between $\mathrm{B}_{\mathrm{A}}, \mathrm{B}_{\mathrm{H}}$, and $\mathrm{P}_{\mathrm{H}}$ at $50^{\circ} \mathrm{C}$ as a function of $\tau_{\mathrm{C}}$.

Figure 22 illustrates the optical microscope photographs of the cross-section for $B_{H}$. Comparing Figs. 22(A) and (B), one can clearly recognize that a large number of pores (complicated structures) appeared in the sample of $W_{0}=54 \%$-d.b. rather than that of $W_{0}=$ $127 \%$-d.b., indicating a growth of the labyrinth factor $(\chi)$. This growth of $\chi$ contributes to the reduction of $\delta$ and is supported by the experimental evidences of the steep reductions of both $\delta D_{0}$ in Fig. 21 and $D e$ in Fig. 19 in the water species $A_{2}$ region.

The $\delta D_{0} \sim \tau_{C}$ plots again demonstrate the hybrid technique to be a useful tool for discriminating between the two water species and among the kind of foods. The drastic change of $\delta D_{0}$ should derive the change of water species from $A_{1}$ to $A_{2}$, suggesting the diffusion mechanism change between the two regions. This idea is strongly supported by experimental evidence as shown in Figure 23. All $E_{\mathrm{D}}$ 's of water species $\mathrm{A}_{2}$ for $\mathrm{B}_{\mathrm{A}}, \mathrm{B}_{\mathrm{H}}$, and $\mathrm{P}_{\mathrm{H}}$ demonstrated a drastic reduction at $C \tau_{C}$ in the water species $A_{2}$ region. This reduction of $E_{D}$ strongly suggests a change in the diffusion mechanism from the water species $\mathrm{A}_{1}$ region. 


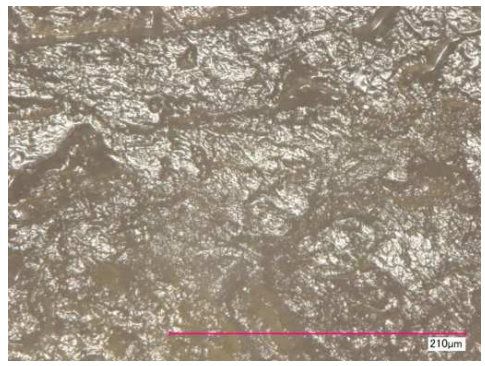

(A)

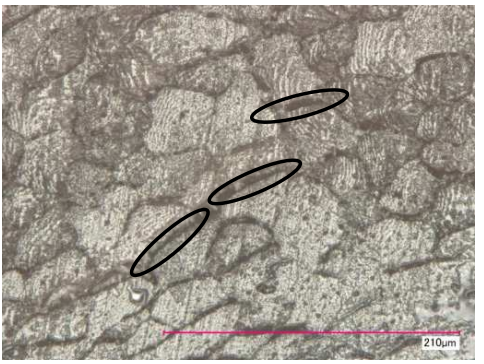

(B)

Fig. 22. Optical microscope photographs $(\times 1000)$ of the cross-section for $\mathrm{P}_{\mathrm{H}},(\mathrm{A})$ : $127 \%$-d.b., (b): 54\%-d.b.

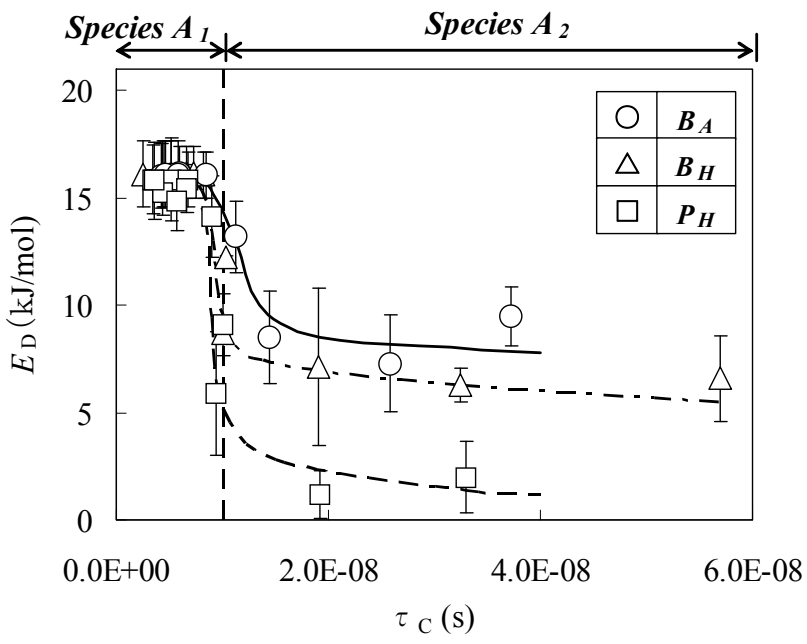

Fig. 23. Comparing behavior of $E_{\mathrm{D}}$ among $\mathrm{B}_{\mathrm{A}}, \mathrm{B}_{\mathrm{H}}$, and $\mathrm{P}_{\mathrm{H}}$ as a function of $\tau_{\mathrm{C}}$ at $50 \sim 70^{\circ} \mathrm{C}$.

\section{A new method for jerky product design using the parameters induced by the hybrid technique}

Our interest is focused on a classification of the 12 jerky products influenced by multifunctional water species. Hills et al. (1999) empirically demonstrated a linear relation between the NMR relaxation rates $\left(1 / T_{2}\right)$ and $a_{w}$. In addition, Hills (1999) derived a theoretical equation to explain the linear relation. Since the relaxation time, $T_{2}$, can be replaced by $\tau_{C}$ using Equation (3), it is proposed that $\mathrm{a}_{\mathrm{w}}$ should be related to $\tau_{\mathrm{C}}$. Figure 24 demonstrates $a_{w}$ as a function of $\tau_{C}$ for the 12 jerky samples. All the samples fell roughly around three straight lines, indicating the existing of three groups. The three lines started from $\mathrm{a}_{\mathrm{w}}=0.92$, which is an identical value independent of the samples and empirically evaluated, meaning a specified value for all kinds of foods (Konishi and Kobayashi, 2010). The $\mathrm{a}_{\mathrm{w}}=0.92$ value always gave $\tau_{\mathrm{C}}=10^{-8} \mathrm{~s}$ independent of the kinds of foods and seasoning species. As has been discussed in the previous section, one can recognize both $\mathrm{a}_{\mathrm{w}}=0.92$ and $\tau_{\mathrm{C}}=10^{-8} \mathrm{~s}$ to be critical values for foods in which the water species drastically changes from 
$A_{1}$ to $A_{2}$ and the pore structure of the food tissue matrix provides regulation of $\varepsilon$ and $\chi$ values accompanied by drastic increases or decreases.

Focusing on the three straight lines in Fig. 24, line-1 generates Group-1 (BJ-5 and PJ-2), line2, Group-2 (BJ-4, BJ-1, PJ-4, BJ-6, and PJ-1), and line-3, Group-3 (PJ-5, BJ-3, BJ-2, and PJ-6). Based on the experimental data presented here, although one cannot demonstrate an exact physical meaning of the three groups' difference, it might be presumed that each group should have the specified seasonings different from others. Concerning the seasonings in the three groups, Group- 1 is characterized by soy sauce, Group-2, by a mixed seasoning such as soy sauce, smoke flavoring, and salt, and Group-3, by a mixed seasoning such as salt, soysauce, and miso sauce. Although each of the three groups could not be distinguished by the chemical engineering (the aw $\sim W_{0}$ curves and the De $\sim W_{0}$ curves) and proton NMR techniques (the $\tau_{C} \sim W_{0}$ curves), the hybrid technique (the aw $\sim \tau_{C}$ linear relation) clearly distinguished the characteristics of the seasonings for the 12 different food products. This evidence strongly demonstrates the hybrid technique to be a useful tool to design various food products requested by the commercial fields.

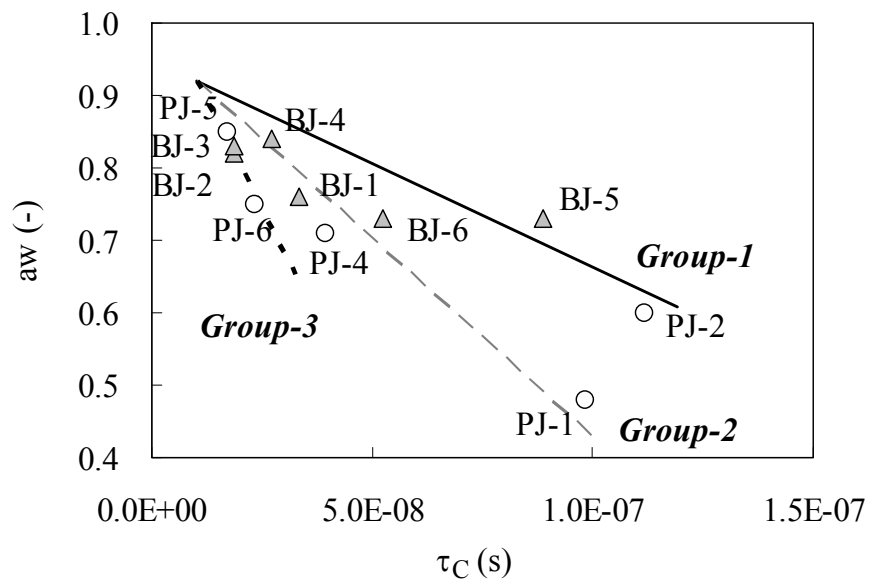

Fig. 24. $\mathrm{a}_{\mathrm{w}}$ as a function of $\tau_{\mathrm{C}}$ for the beef and pork jerkies.

\section{Conclusions}

The hybrid of the proton NMR technique and the chemical engineering technique was applied to discriminate the 12 commercially distributed jerkies, salmon, $\mathrm{B}_{\mathrm{A}}, \mathrm{B}_{\mathrm{H}}$, and $\mathrm{P}_{\mathrm{H}}$ and to distinguish between the two water species, $\mathrm{A}_{1}$ and $\mathrm{A}_{2}$, by using four parameters: $D e, \tau_{\mathrm{C}}$, $N_{\mathrm{P}}$, and $W_{0}$.

1. The dehydration and adsorption of the water species, $A_{1}$ and $A_{2}$, retained in the foods were reversibly repeated and the transformation between the two water species was reproducible.

2. The proton NMR technique and the chemical engineering technique could respectively not discriminate among the $\tau_{\mathrm{C}} \sim W_{0}$ curves and among the $\mathrm{a}_{\mathrm{w}} \sim W_{0}$ curves obtained for the foods. Although the computer simulation model proposed by the chemical engineering technique generated a good fitting against the dehydration response 
curves, the unknown parameters evaluated by the curve fitting, $\beta_{1}$ and $\beta_{2}$, were recognized as meaningless.

3. The hybrid technique proposed demonstrates a clear discrimination between water species $A_{1}$ and $A_{2}$, divided at the critical value of $C_{\tau_{C}}=10^{-8} \mathrm{~s}$, where the drastic change in the values of $D e, E_{\mathrm{D}}$, and $N_{\mathrm{P}}$ appeared. The physical meaning of $C \tau_{\mathrm{C}}$ was understood as a drastic change in the pre-exponential factor of $D e$ derived from the change in the food tissue matrix due to dehydration.

4. Using the hybrid technique, a variety of food products could easily be designed by changing the value of $\tau_{C}$ even though the values of $a_{w}$ are identical. The meat jerkies commercially distributed in Japan were reasonably classified into three groups characterized by the three $\mathrm{a}_{\mathrm{w}} \sim \tau_{\mathrm{C}}$ straight lines. The advantage of the hybrid technique brought a conclusion that the $\mathrm{a}_{\mathrm{w}} \sim \tau_{\mathrm{C}}$ straight lines give characteristic slopes depending on the seasonings of the 12 jerkies. This could be useful in designing a variety of food products.

\section{Nomenclature}

$\begin{array}{ll}B_{A} & \text { beef meat produced in Australia }(-) \\ B_{H} & \text { beef meat produced in Hokkaido, Japan }(-) \\ D & \text { moisture diffusion coefficient }\left(\mathrm{m}^{2} / \mathrm{h}\right) \\ D_{0} & \text { frequency factor of } D\left(\mathrm{~m}^{2} / \mathrm{h}\right) \\ D e & \text { effective water diffusion coefficient }\left(\mathrm{m}^{2} / \mathrm{h}\right) \\ D e^{0} & \text { pre-exponential factor of De }\left(\mathrm{PF}=\delta \cdot \mathrm{D}_{0}, \mathrm{~m}^{2} / \mathrm{h}\right) \\ E_{D} & \text { activation energy of water diffusivity }(\mathrm{kJ} / \mathrm{mol}) \\ H & \text { Planck constant }(\mathrm{erg} . \mathrm{s}) \\ I & \text { nuclear spin quantum number of water proton }(=0.5)(--) \\ K & \text { Boltzmann constant }(\mathrm{erg} / \mathrm{deg}) \\ k_{S} & \text { mass transfer coefficient of strongly restricted water }(\mathrm{h}-1) \\ k_{w} & \text { mass transfer coefficient of weakly restricted water }\left(\mathrm{h}^{-1}\right) \\ L_{a} & \text { half distance of a-axis of the rectangular sample }(\mathrm{m}) \\ L_{b} & \text { half distance of b-axis of the rectangular sample }(\mathrm{m}) \\ L_{c} & \text { half distance of c-axis of the rectangular sample }(\mathrm{m}) \\ M_{t} & \text { magnitude of magnetization vector }(-) \\ M_{0} & \text { magnitude of macroscopic equilibrium magnetisation vector }(-) \\ N_{P} & \text { hardness of meat products }\left(\mathrm{Newton} / \mathrm{m}^{2}\right) \\ P_{H} & \text { pork meat produced in Hokkaido, Japan }(-) \\ R & \text { gas constant }(=8.314 \mathrm{~J} / \mathrm{K} \text { mol) } \\ r & \text { proton-proton distance of water molecule }(=0.16 \mathrm{~nm}) \\ \Delta S & \text { activation entropy }(\mathrm{kJ} / \text { mol) } \\ T_{2} & \text { spin-spin relaxation time of water proton }(\mathrm{s}) \\ T_{D} & \text { drying temperature }\left({ }^{\circ} \mathrm{C}\right) \\ t & \text { drying time }(\mathrm{h}) \\ t s & \text { spin locking pulse length }(\mathrm{s}) \\ W & \text { inater content at the drying time }(\%-\mathrm{d} . \mathrm{b} .) \\ W_{0} & \text { equilibrium water water content }(\%-\mathrm{d} . \mathrm{b} .) \\ W_{D} & \end{array}$




$\begin{array}{ll}W_{R} & \text { the water ratio }\left(=(\mathrm{W}-\mathrm{We}) /\left(\mathrm{W}_{\mathrm{D}}-\mathrm{We}\right)\right) \\ W_{R 1} & \text { the proportion of the strongly restricted water amount }(-) \\ W_{R 2} & \text { the proportion of the weakly restricted water amount }(-) \\ W_{R S} & \text { the ratio of the strongly restricted water species }(-) \\ W_{R W} & \text { the ratio of the weakly restricted water species }(-) \\ W_{S} & \text { the amount of strongly restricted water species }(\%-\mathrm{d} . \mathrm{b} .) \\ W_{W} & \text { the amount of weakly restricted water species }(\%-\mathrm{d} . \mathrm{b} .)\end{array}$

\section{Greek letters}

$\begin{array}{ll}\beta_{1} & \text { constant evaluated by the curve fitting simulation }\left(\mathrm{m}^{-2}\right) \\ \beta_{2} & \text { constant evaluated by the curve fitting simulation }\left(\mathrm{m}^{-2}\right) \\ \varepsilon & \text { porosity of the food tissue }(-) \\ \pi & \text { the ratio of the circumference of a circle to its diameter }(=3.14) \\ \gamma & \text { gyromagnetic ratio of proton }\left(=2.675 \times 10^{8} \mathrm{rad} \cdot \mathrm{T}^{-1} \cdot \mathrm{s}^{-1}\right) \\ \hbar & \text { modified Plank's constant }\left(=6.63 \times 10^{-34} \mathrm{~J} \cdot \mathrm{s}\right) \\ \omega_{0} & \text { resonance frequency }\left(=3.14 \times 10^{9} \mathrm{~s}^{-1}\right) \\ \tau_{C} & \text { correlation time of water proton }(\mathrm{s}) \\ C \tau_{C} & \text { critical correlation time of water proton }(\mathrm{s}) \\ \chi & \text { labyrinth factor of the meat tissue }(-) \\ \delta & \text { diffusibility }(=\varepsilon / \mathrm{X})(-)\end{array}$

\section{Acknowledgment}

This work was financially supported by the Cooperation of Innovation Technology and Advanced Research in Evolution Area (City Area) from the Japanese Ministry of Education, Culture, Sports, Science, and Technology. The authors wish to thank Associate Professor Koichi Miura, Kitami Institute of Technology, for his assistance with the proton NMR analysis.

\section{References}

Abragam, A., (1963). The Principles of Nuclear Magnetism. Oxford at the Clarend Press, p347349.

Andreu, J. \& Stamatopoulos, A.A. (1986). Durum wheat pasta drying kinetics. Lebensm. Wiss. u.-Technol., 19 , 448-456.

Belton, P.S.; Gil, A.M.; Webb, G.A., \& Rutledge, D., Eds.(2003). Magnetic resonance in food science-latest developments, The Royal Society of Chemistry, Cambridge.

Chhinnan, M.S. (1984). Evaluation of selected mathematical models for describing thin-layer drying of in-shell pecans. Trans. ASAE, 27(2), 610-615.

Fennema, O.(1976). In principles of food science, Part 1, Marcel Dekker, New York.

Hills, B.P. (1999). NMR studies of water mobility in foods. In"Water Management in the Design and Distribution of Quality Foods" ISOPOW 7(Y.H. Roos, R.B. Leslie, and P.J.Lillford, eds) Technomic Publishing, Lancaster, PA.

Hills, B. P., Manning, C. E. \& Godward, J. (1999). A multistate theory of water relations in biopolymer systems. In: Advances in Magnetic Resonance in Food Science (edited by P. S. Belton, B. P. Hill and G. A. Webb). Pp.45-62. Cambridge, UK: Royal Society of Chemistry. 
Jason, A.C.(1958). A Study of evaporation and diffusion processes in the drying of fish muscle in fundamental aspects of dehydration of food stuffs, ed. Society of Chemical Industry. McMillan, London, pp.103-134.

Kannan, D. and Bandyopadhyay, S. (1995). Drying characteristics of a tropical marine fish slab. J.Food Sci. Technol., 32(1), 13-16.

Konishi, Y.; Horiuchi, J., \& Kobayashi, M.(2001). Dynamic evaluation of the dehydration response curves of foods characterized by a poultice-up process using a fish-paste sausage-I. Determination of the mechanisms for moisture transfer, Drying Technology, 19(7), 1253-1269

Konishi, Y.; Horiuchi, J., \& Kobayashi, M.(2001). Dynamic evaluation of the dehydration response curves of foods characterized by a poultice-up process using a fish-paste sausage-II, A new tank model for a computer simulation, Drying Technology, 19(7), 1271-1285.

Konishi, Y.;Miura, K. \& Kobayashi, M.(2003). Drying efficiency design using multifunctional dynamics of water molecules in foods-H-NMR analysis of a fish paste sausage and squid, AIDIC Conference series, vol.6, 183-190.

Konishi, Y. \& Kobayashi, M.(2009). Quantitative evaluation of the design parameters requested in beef and pork drying operation, AIDIC Conference Series, 9, 177-186.

Konishi, Y., \& Kobayashi, M., (2010). Food product design using the water species as a probe molecule. Annual meeting of Japanese Society of Food Engineering.

Konishi, Y., Kobayashi, M., \& Miura, K. (2010). Characeterization of water species revealed in the drying operation of Todarodes pacificus Steenstrup using water proton NMR analysis, International Journal of Food Science and Technology., 45.1889-1894.

Konishi, Y. \& Kobayashi, M.(2011). Dynamism of the water species as a probe molecule in food, Chemical Engineering Transactions, Ed. Sauro Pierucci, 24, 475-480.

Labuza, T.P., Tannenbaum, S.R., \& Karel,M. (1970), Water Content and Stability of Low moisture and intermediate moisture foods. Food Technol.24, 543-550.

Litchfield, J.B. \& Okos, M.R. ,1992. Moisture diffusivity in pasta during drying. J. Food Engng., 17, 117-142.

Madamba, P. S., Driscoll, R. H. \& Buckle, K. A.(1996). The thin-layer drying characteristics of garlic slices. J. Food Engng., 29, 75-97.

Noomhorm, A. \& Verma, L.R.(1986). Generalized single layer rice drying models. Trans. ASAE., 29(2), 587-591.

Rockland, L.B. and Stewart, G.F., Eds.(1981). International symposium on properties of water, water activity: Influences on food quality, Academic Press Inc., London.

Schmidt, S.J., Water and Solids Mobility in Foods, (2004). Advances in Food and Nutrition research, volume 48, 2004, Edited by S.L. Taylor, Elsevier

Thompson, T.L., Peart, R.M. \& Foster, G.H. (1968). Mathematical simulation of corn drying (A new model). Trans.ASAE.,24(3),582.

Waananen, K.M. \& Okos, M.R. (1996). Effect of porosity on moisture diffusion during drying of pasta. J. Food Engng., 28, 121-137. 


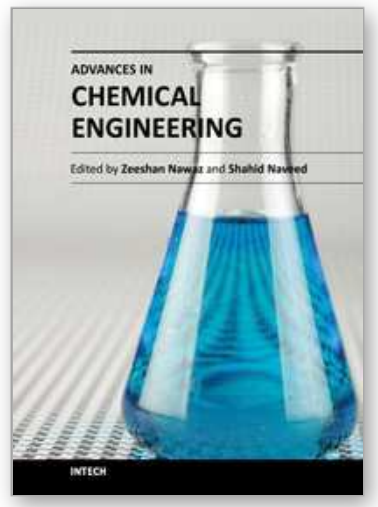

\author{
Advances in Chemical Engineering \\ Edited by Dr Zeeshan Nawaz
}

ISBN 978-953-51-0392-9

Hard cover, 584 pages

Publisher InTech

Published online 23, March, 2012

Published in print edition March, 2012

Chemical engineering applications have been a source of challenging optimization problems in terms of economics and technology. The goal of this book is to enable the reader to get instant information on fundamentals and advancements in chemical engineering. This book addresses ongoing evolutions of chemical engineering and provides overview to the sate of the art advancements. Molecular perspective is increasingly important in the refinement of kinetic and thermodynamic molding. As a result, much of the material was revised on industrial problems and their sophisticated solutions from known scientists around the world. These issues were divided in to two sections, fundamental advances and catalysis and reaction engineering. A distinct feature of this text continues to be the emphasis on molecular chemistry, reaction engineering and modeling to achieve rational and robust industrial design. Our perspective is that this background must be made available to undergraduate, graduate and professionals in an integrated manner.

\title{
How to reference
}

In order to correctly reference this scholarly work, feel free to copy and paste the following:

Yasuyuki Konishi and Masayoshi Kobayashi (2012). Challenging Evaluation of the Hybrid Technique of Chemical Engineering - Proton NMR Technique for Food Engineering, Advances in Chemical Engineering, Dr Zeeshan Nawaz (Ed.), ISBN: 978-953-51-0392-9, InTech, Available from:

http://www.intechopen.com/books/advances-in-chemical-engineering/challenging-evaluation-of-a-hybridmethod-of-chemical-engineering-proton-nmr-technique-for-the-food-

\section{INTECH}

open science | open minds

\section{InTech Europe}

University Campus STeP Ri

Slavka Krautzeka 83/A

51000 Rijeka, Croatia

Phone: +385 (51) 770447

Fax: +385 (51) 686166

www.intechopen.com

\section{InTech China}

Unit 405, Office Block, Hotel Equatorial Shanghai

No.65, Yan An Road (West), Shanghai, 200040, China

中国上海市延安西路65号上海国际贵都大饭店办公楼 405 单元

Phone: +86-21-62489820

Fax: $+86-21-62489821$ 
(C) 2012 The Author(s). Licensee IntechOpen. This is an open access article distributed under the terms of the Creative Commons Attribution 3.0 License, which permits unrestricted use, distribution, and reproduction in any medium, provided the original work is properly cited. 